\title{
Winter Storm Tracks and Related Weather in the NCEP Climate Forecast System Weeks 3-4 Reforecasts for North America
}

\author{
KATHERINE E. LUKENS \\ Department of Atmospheric and Oceanic Science, and Cooperative Institute for Climate and Satellites-Maryland, \\ Earth System Science Interdisciplinary Center, University of Maryland, College Park, College Park, Maryland \\ ERNESTO HUGO BERBERY \\ Cooperative Institute for Climate and Satellites-Maryland, Earth System Science Interdisciplinary Center, \\ University of Maryland, College Park, College Park, Maryland
}

(Manuscript received 6 July 2018, in final form 1 April 2019)

\begin{abstract}
This article examines to what extent the NCEP Climate Forecast System (CFS) weeks 3-4 reforecasts reproduce the CFS Reanalysis (CFSR) storm-track properties, and if so, whether the storm-track behavior can contribute to the prediction of related winter weather in North America. The storm tracks are described by objectively tracking isentropic potential vorticity (PV) anomalies for two periods (base, 1983-2002; validation, 2003-10) to assess their value in a more realistic forecast mode. Statistically significant positive PV biases are found in the storm-track reforecasts. Removal of systematic errors is found to improve general storm-track features. CFSR and Reforecast (CFSRR) reproduces well the observed intensity and spatial distributions of storm-track-related near-surface winds, with small yet significant biases found in the stormtrack regions. Removal of the mean wind bias further reduces the error on average by $12 \%$. The spatial distributions of the reforecast precipitation correspond well with the reanalysis, although significant positive biases are found across the contiguous United States. Removal of the precipitation bias reduces the error on average by $25 \%$. The bias-corrected fields better depict the observed variability and exhibit additional improvements in the representation of winter weather associated with strong-storm tracks (the storms with more intense PV). Additionally, the reforecasts reproduce the characteristic intensity and frequency of hazardous strong-storm winds. The findings suggest a potential use of storm-track statistics in the advancement of subseasonal-to-seasonal weather prediction in North America.
\end{abstract}

\section{Introduction}

The subseasonal-to-seasonal (S2S) time frame (ranging from 2 weeks to about 2 months) has largely been considered a major gap in operational forecasting as it represents a range that bridges weather and climate prediction and is not well defined by either category. The need to address this gap and advance $\mathrm{S} 2 \mathrm{~S}$ prediction is internationally recognized as a high priority (Brunet et al. 2010; Vitart et al. 2012, 2017). Studies suggest that identifying sources of predictability at S2S scales could considerably benefit society by offering actionable information that could 1) facilitate disaster mitigation efforts and help optimize the security of life and property and 2) enhance management practices across multiple

Corresponding author: Ernesto Hugo Berbery, berbery@umd.edu sectors including agriculture, water security, public health, transportation, and energy (e.g., Shapiro et al. 2010; White et al. 2017; Vitart et al. 2012, 2017).

High-impact weather events (e.g., droughts, floods, heat waves, wildfires, and persistent periods of cold) have a history of physically and fiscally devastating society. This is also the case of extratropical storms that have the potential to cause structural and economic damage comparable to hurricanes, particularly in areas that experience a fast succession of storms (Mailier et al. 2006). In the last few decades in the United States, weather-related losses have increased (Kunkel et al. 1999; Pielke and Carbone 2002; Karl et al. 2008), and the vulnerability to storm-related loss is expected to rise with projected increases in strong-storm frequency and intensity (Karl et al. 2008; Shapiro et al. 2010; Kunkel et al. 2013; Lawrimore et al. 2014). As such, the study of 
storm tracks and related impacts is critical for understanding the effects of destructive weather and anticipating weather-related fluctuations in the state of the economy, particularly in winter.

Winter weather in North America is largely influenced by the zonally oriented Pacific storm track located over the North Pacific Ocean, and the southwestnortheast-tilted Atlantic storm track that extends from eastern North America into the higher latitudes of the North Atlantic Ocean (Hawcroft et al. 2012; Ma and Chang 2017). Over land, precipitation tends to increase upstream of high orography due to a combination of orographic uplifting and a strong upper-level zonal flow that drives storm intensification and rapid storm succession (Garreaud 2007). Shifts in storm-track behavior yield corresponding changes in the intensity and frequency of extreme precipitation and wind events. For instance, a northward shift of the Pacific storm track can enhance winter precipitation in western North America (Chang et al. 2002; Salathé 2006; Kunkel et al. 2012; Pfahl and Wernli 2012; Ma and Chang 2017). In the midlatitudes, storms account for more than half of the total winter precipitation (Catto et al. 2012; Hawcroft et al. 2012; Pfahl and Wernli 2012), with the stronger storms making up to $16 \%$ of all storms but contributing in certain regions of North America about $30 \%-50 \%$ of the total storm precipitation (Lukens et al. 2018). Moreover, strong-storm tracks (those with high PV maximum intensity) in winter have a significant imprint on nearsurface winds and precipitation that could induce considerable structural and economic loss in North America (Lukens et al. 2018).

Recent studies have found that there is significant skill in the seasonal prediction of midlatitude storm tracks and extremes, particularly in winter (e.g., Yang et al. 2015). Further, studies indicate that there are numerous potential sources of S2S predictability that can influence storm-track variability and thus subseasonal storm-track prediction. For instance, convection in the tropical Pacific that is associated with the Madden-Julian oscillation (MJO) and excites Rossby wave activity has been found to largely contribute to intraseasonal (3090 day) storm-track variability over North America (Grise et al. 2013; Guo et al. 2017; Zheng et al. 2018). In addition, variations in stratospheric circulation anomalies tend to precede shifts in the storm tracks by $\sim 60$ days (Baldwin and Dunkerton 2001). If forecast models contain storm-track-related S2S signals and account for potential sources of predictability, then the characterization of storm tracks in long-term forecasts could help advance S2S weather prediction by providing key information that may not be acquired from standard wind and precipitation forecasts.
Storm tracks can be described in an isentropic potential vorticity (PV) framework (Hoskins and Hodges 2002). PV includes both absolute vorticity and static stability (Hoskins et al. 1985), and thus describes the major dynamic and thermodynamic properties of atmospheric circulation. Unlike mean sea level pressure and similar variables that tend to be dominated by large scales, PV anomalies allow for the earlier detection of small-scale features like cyclogenesis (Hoskins and Hodges 2002). Moreover, PV is a preferred dynamic tracer for cyclones as a parcel conserves PV in an adiabatic and frictionless flow (Holton 2004). In the Northern Hemisphere $(\mathrm{NH})$, a strong positive PV anomaly in the upper troposphere that is not necessarily restricted to the tropopause induces a cyclone near that level that can, in turn, induce a positive anomaly and cyclone at the surface (Hoskins et al. 1985; Holton 2004; Hoskins 2015).

This study evaluates storm-track behavior and related winter weather in submonthly (weeks 3-4) forecasts of the NCEP Climate Forecast System Reanalysis (CFSR) and Reforecast (CFSRR) system. Reforecasts, or retrospective forecasts, are historical predictions of past events used for the calibration and skill assessment of operational model forecasts. Two questions are addressed in this article: 1) can CFS weeks 3-4 reforecasts reproduce the dynamic properties of storm tracks, and 2) if so, does the information carried in those properties contribute to the prediction of the expected severe weather at those time scales in North America?

The structure of the paper is as follows: section 2 describes the datasets, storm-tracking methodology, and performance metrics. Section 3 discusses the storm-track properties as identified in CFSRR at subseasonal scales, and the advantages of removing the systematic bias. Section 4 discusses the stormtrack-related weather reforecasts and corresponding results from the bias correction, while section 5 describes a similar analysis but for weather related to strong storms. Section 6 summarizes the findings and implications.

\section{Data and methods}

\section{a. Climate Forecast System Reanalysis}

The CFSR (Saha et al. 2010a) product is a complete global reanalysis dataset generated by coupling atmosphere, ocean, land surface, and sea ice data every $6 \mathrm{~h}$. The atmospheric data are archived at 64 vertical pressure-sigma levels on a $0.5^{\circ} \times 0.5^{\circ}$ latitude-longitude grid. Advantages to using CFSR over past reanalyses at 
NCEP include its higher temporal and spatial resolutions, updated physics, and the coupled assimilation (Saha et al. 2010b; Wang et al. 2011). For the purposes of this study, CFSR data are considered "truth" and are examined for $28 \mathrm{NH}$ winters (DJF; 1983-2010).

\section{b. CFSR Reforecasts}

CFSRR (Saha et al. 2014a) is a reforecast dataset created at NCEP for calibrations and skill assessments of operational forecasts produced by NCEP's CFS version 2 model (CFSv2; Saha et al. 2014b). Nine-month reforecasts are generated using CFSR data as initial conditions that are 5 days apart, and they are archived every $6 \mathrm{~h}$ on a $1^{\circ} \times 1^{\circ}$ latitude-longitude grid. Relative to the CFSR system, modifications were made to the atmosphere and land models used to produce the reforecast data to mollify growing biases found in relevant variables (Saha et al. 2014b).

This study focuses on the analysis of a specific range within the S2S gap in predictability, that is, the weeks 3-4 reforecasts taken from the 9-month retrospective prediction runs initialized at 0000 UTC. "Weeks $3-4$ " is defined as the period of historical reforecasts that extend from days 14 to 28 from the initialization date. For instance, 15 November initial conditions are used to generate reforecasts for 1-15 December, 1 December initial conditions are used to generate reforecasts for 16-31 December, and so on for DJF.

The 28-yr period is divided into a $20-\mathrm{yr}$ base period (1983-2002) where biases are computed and an 8-yr validation period (2003-10) where bias corrections are applied to test if the bias-corrected CFS weeks 3-4 reforecasts improve the representation of storm tracks when working in forecast mode.

\section{c. CPC unified gauge-based daily precipitation}

The Climate Prediction Center (CPC) unified gaugebased analysis of daily precipitation for the contiguous United States (CONUS; Xie et al. 2010) is an observational precipitation dataset that is part of a suite of products in the CPC Unified Precipitation Project. The project combines all precipitation sources at the CPC to create a consistent suite of products that have improved quality relative to similar gauge-based analyses (Xie et al. 2010). Datasets are constructed from inputs of quality controlled gauge and satellite data using the optimal interpolation (OI) objective analysis technique (Xie et al. 2007; Chen et al. 2008). The data over CONUS are taken from a combined number of about 8000 daily precipitation reports and are archived on a $0.25^{\circ} \times 0.25^{\circ}$ latitude-longitude grid, with daily accumulations ending at 1200 UTC (Chen et al. 2008). For verification purposes in this study, CPC daily
TABLE 1. Values of average $\mathrm{PV}_{320}$ maximum $\left(\overline{\mathrm{PV}}_{x}\right)$ and $\mathrm{PV}_{x}$ standard deviation (SD) used to compute all-storm threshold $T_{\text {all }}$ for the reanalysis and weeks 3-4 reforecasts. Thresholds are obtained from all identified cyclones in the $\mathrm{NH}$ winter in the base period 1983-2002. Units are PVU.

\begin{tabular}{llcl}
\hline \hline NH 1983-2002 & $\overline{\mathrm{PV}}_{x}$ & $\left(\mathrm{PV}_{x}\right)_{\mathrm{SD}}$ & $T_{\text {all }}$ \\
\hline Reanalysis & 3 & 1.3 & 1 \\
Reforecasts & 3.3 & 1.7 & 0.75 \\
\hline
\end{tabular}

precipitation observations over CONUS are examined for $28 \mathrm{NH}$ winters in DJF (1983-2010). Prior to plotting the CPC precipitation means are regridded to $1^{\circ} \times 1^{\circ}$ for comparison with the coarser resolution weeks 3-4 reforecasts.

\section{d. Storm tracking}

Following the methodology of Hoskins and Hodges (2002), storms are identified as PV maxima that exceed a certain threshold and are objectively tracked throughout their life cycles. Prior to the identification and tracking of storms, the data are filtered to a spectral $\mathrm{T} 42$ resolution to reduce noise. The $320-\mathrm{K}$ isentrope is chosen as the level of analysis as it resides in the mid- to upper troposphere near the upper-level jet stream where characteristics of cyclones are often identified (e.g., Hoskins and Hodges 2002). After the tracking of storms is completed, spatial and temporal filters are applied to remove short-duration storms, leaving only those that last at least 2 days and travel farther than $1000 \mathrm{~km}$ (Hodges 1999; Hoskins and Hodges 2002).

For this analysis, PV anomalies on the $320-\mathrm{K}$ surface (hereafter $\mathrm{PV}_{320}$ ) are considered to be extratropical cyclones (or storms) if their intensities exceed the low threshold of 0.5 PVU (where $1 \mathrm{PVU}=10^{-6} \mathrm{~K} \mathrm{~m}^{2} \mathrm{~kg}^{-1} \mathrm{~s}^{-1}$ ). This allows for the retention of a large number of storms in the analysis while still capturing weak cyclogenesis features (see Lukens et al. 2018, their Fig. 2). Following Lukens et al. (2018), an additional filter is also applied to remove any weak storms with a maximum intensity smaller than a relatively low threshold $T_{\text {all }}$ defined as

$$
T_{\text {all }}=\overline{\mathrm{PV}}_{x}-1.5 \times\left(\mathrm{PV}_{x}\right)_{\mathrm{SD}},
$$

where $T_{\text {all }}$ refers to the threshold to identify all storms, $\overline{\mathrm{PV}}_{x}$ is the maximum $\mathrm{PV}$ intensity averaged for all identified cyclones in the $\mathrm{NH}$, and SD is the standard deviation. Storms that adhere to these criteria shape the "all-storm tracks." Table 1 shows the values used to compute $T_{\text {all }}$ for the reanalysis and uncorrected reforecasts. Both thresholds were obtained from the base period 1983-2002 and are used for both the base period 
and validation period diagnostics. Differences in the thresholds for the two datasets are due to differences in both the average $\mathrm{PV}$ maximum and $\mathrm{PV}_{x}$ standard deviation.

Once all storms in the all-storm tracks are identified, a number of statistics can be derived to describe the main properties of the storm tracks: a track density statistic is defined as the number of single cyclone tracks per unit area, highlighting regions where storms tend to propagate, representing the storm-track pattern. By identifying the points where the anomaly first exceeds the low PV threshold (0.5 PVU), we obtain the cyclogenesis density, while the same procedure for points where the PV has gone below the threshold defines cyclolysis densities. All density statistics are scaled to number densities (per unit area per month, where the unit area is equivalent to a $5^{\circ}$ spherical cap or $\sim 10^{6} \mathrm{~km}^{2}$ ). Further details on the method are discussed in Hodges (1996, 2008).

The approach of Lukens et al. (2018) is used to relate near-surface winds and precipitation to the storm tracks. Every $6 \mathrm{~h}$, near-surface winds are related to the storm tracks if they are found within a $5^{\circ}$ circular area around each cyclone center, where the winds tend to be strongest (Field and Wood 2007). For precipitation, a circular area of $12^{\circ}$ around each storm center is chosen as this represents a typical size of a precipitation footprint of storms in the NH winter (Hawcroft et al. 2012, 2016; Booth et al. 2018). To highlight the midlatitude storm-track regions in figures depicting the stormtrack-related weather, grid points are masked if the average number of storms falls below 0.5 storms per unit area per month.

The root-mean-square error (RMSE) is used to assess the accuracy of the reforecasts of stormtrack intensity and storm-track-related weather relative to the reanalysis, that is, by measuring how well the seasonal variability is represented in the reforecasts:

$$
\mathrm{RMSE}=\sqrt{\frac{1}{n} \sum_{i=1}^{n}\left(Y_{i}-X_{i}\right)^{2}},
$$

where $X$ and $Y$ are the storm-track $\mathrm{PV}$ intensities or related weather variables for the reanalysis and the reforecasts respectively averaged for each winter $i$, and where $n$ is the total number of winters in the period. Last, we examine the ratio (RSR) of the RMSE of the reforecasts to the standard deviation of the reanalysis. In general, lower RSR values are indicative of a better model performance (Moriasi et al. 2007), and we adopt this concept in our findings for the validation period.

\section{Storm tracks in the reforecasts}

\section{a. PV intensity}

Following Eq. (1), the minimum $\mathrm{PV}_{x}$ intensity threshold to identify all storms in the reanalysis is $1 \mathrm{PVU}$, while the threshold for all storms in the reforecasts is $0.75 \mathrm{PVU}$ (see Table 1). According to Eq. (1), the higher values of the reforecast $\overline{\mathrm{PV}}_{x}$ are compensated by the higher values of $\left(\mathrm{PV}_{x}\right)_{\mathrm{SD}}$, resulting in the lower threshold. The differences between CFSR and CFSRR diagnostics will be the subject of our analysis in this section.

The bias in storm-track intensity will be computed as

$$
\text { bias }=\frac{1}{n} \sum_{i=1}^{n}\left(Y_{i}-X_{i}\right),
$$

where $X$ and $Y$ are the storm-track PV intensities for the reanalysis and the reforecasts respectively averaged for each winter $i$, and where $n$ is the total number of winters in the 1983-2002 period.

Figure 1 presents the winter mean $\mathrm{PV}_{320}$ intensity over all the points along the all-storm tracks in the base period 1983-2002. In the reanalysis (Fig. 1a), the midlatitude storm tracks are most intense over the eastern North Pacific and western North Atlantic Oceans as well as over the western United States. Over land, an intensity maximum is found over the Rocky Mountains and likely represents a combination of the reinvigoration of westerly Pacific cyclones after they are deflected southward and the rapid development of new cyclones east of the mountain range (Brayshaw et al. 2009; Chang 2009). The intensity maximum in western North America is primarily an upper-level feature (Hoskins and Hodges 2002) that leads to surface cyclone generation farther east. This is supported by Fig. 7 of Lukens et al. (2018) that shows stronger surface storm winds farther east of the upper-level intensity maximum.

A similar characterization of winter storm-track intensity in CFSRR is done for the weeks 3-4 reforecasts (Fig. 1b). While the spatial distribution of intensity maxima resembles that in the reanalysis, the magnitude is greater virtually everywhere in the midlatitude stormtrack regions. The difference between the reanalysis and the reforecast $\mathrm{PV}_{320}$ intensity (Fig. 1c) represents the statistically significant $(p$ value $<0.05)$ winter average systematic error or bias as given by Eq. (3). The reforecasts exhibit large overestimations of the strength of the storm tracks in the lower midlatitudes over the oceans and in the high latitudes over northeastern Canada. Significant overestimation is also found in the southwestern and northeastern United States.

To assess whether a more realistic description of the storm-track intensity in the reforecasts is possible, 


\section{All-Storm-Track Mean PV Intensity for 1983-2002}

(a) Reanalysis PV

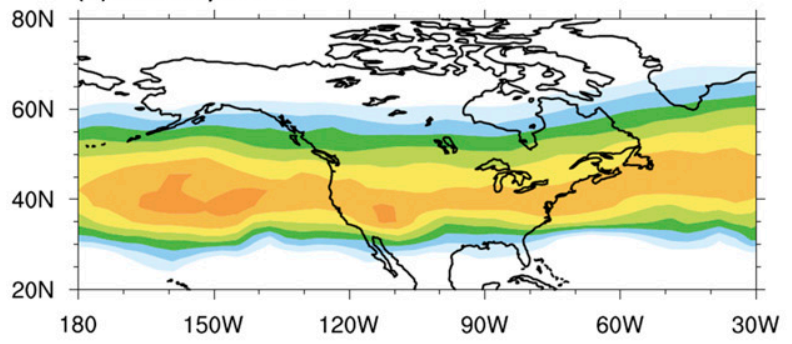

(b) PV Reforecast

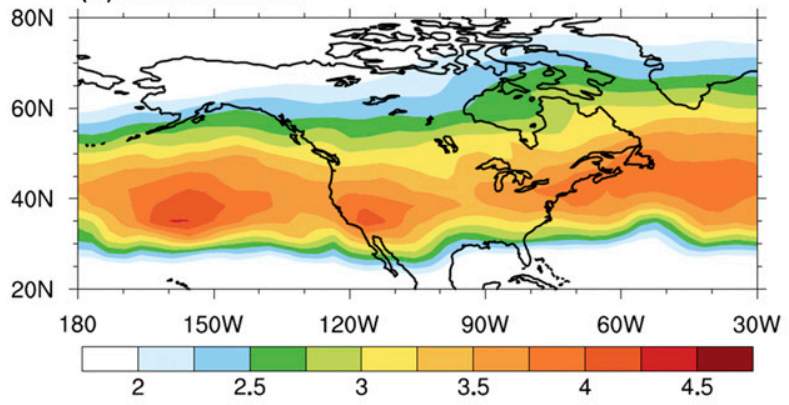

(c) Bias in PV

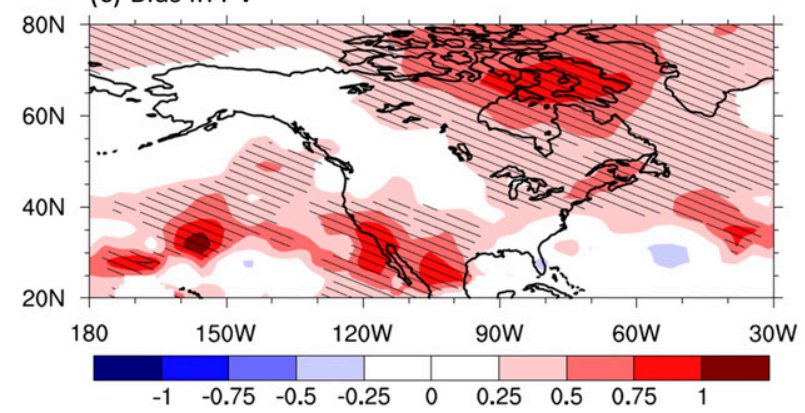

(d) Bias-corrected PV Reforecast

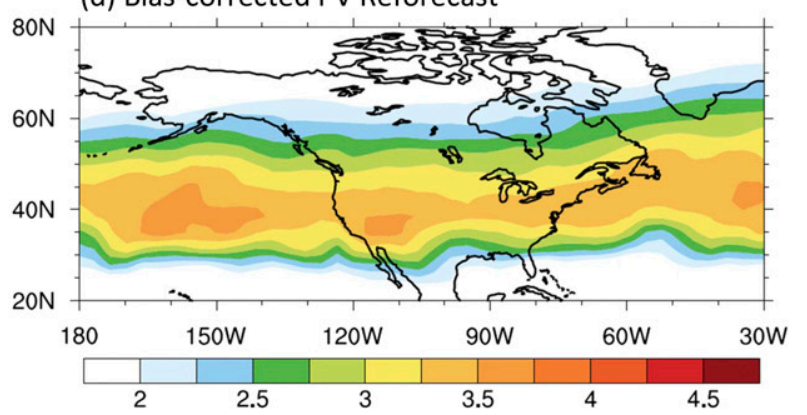

FIG. 1. Mean PV intensity of points along the all-storm tracks during DJF for the base period 1983-2002. (a) CFS reanalysis; (b) weeks 3-4 reforecast; (c) bias (reforecast minus reanalysis), where hatched regions are statistically significant $(p<0.05)$; and (d) bias-corrected weeks 3-4 reforecast. The contour interval for all panels is 0.25 PVU. Areas with less than 0.5 storms per $10^{6} \mathrm{~km}^{2}$ per month in CFSR are masked. the $\mathrm{PV}_{320}$ systematic bias is then removed from each reforecast at every forecast time that storm centers are identified, and the diagnostics are recomputed. If the intensity of a bias-corrected cyclone at a given time step falls below the minimum intensity threshold (0.5 PVU), then the cyclone at that time step is not retained in the bias-corrected storm-track analysis. All cyclones that are retained are used to calculate new statistics of bias-corrected storm-track behavior. The bias correction applied to the reforecasts is found to reduce the error in the all-storm-track intensity and results in the adjusted intensity reforecast shown in Fig. 1d. Notably, the corrected reforecast exhibits a closer resemblance to the storm-track intensity in the reanalysis in both magnitude and spatial distribution (see Fig. 1a).

The mean $\mathrm{PV}_{320}$ intensity over all the points along the all-storm tracks in the validation period (2003-10) is shown in Fig. 2. The reanalysis (Fig. 2a) corresponds well with that for the base period 1983-2002 (see Fig. 1a), despite slightly higher intensities in the midlatitudes over the oceans. As in the base period, the uncorrected weeks 3-4 reforecasts in the validation period (Fig. 2b) overestimate the storm-track intensity in the midlatitudes, particularly over the oceans. When the 1983-2002 bias is removed from each of the 2003-10 reforecasts and the mean all-storm-track intensity is recomputed for the validation period, the results show improvements (Fig. 2c). Although some overestimation in the intensity still remains, the bias correction reduces a considerable portion of the error in the midlatitudes indicating the effectiveness of the approach.

Figures $2 \mathrm{~d}-\mathrm{g}$ describe the performance of the reforecasts before and after the PV bias correction. The SD of PV intensity (Fig. 2d, color shades) is highest in the lower midlatitudes over the oceans and elsewhere is quite low ( $<0.5$ PVU). Relative to the SD, the RMSE of the uncorrected reforecasts (Fig. 2e, contours) is high throughout the storm-track regions. This is reflected in the ratio RSR for PV intensity (Fig. 2e, color shades) that depicts large magnitudes over the northeastern North Atlantic Ocean and North America where statistically significant biases are found (see Fig. 1c). The bias correction reduces the relatively large RMSE and RSR in these regions (Fig. 2f), indicating improved CFSRR performance in terms of storm PV. A decrease (increase) in the percent change in RMSE (Fig. 2g) highlights areas where the representation of all-storm-track intensity improves (worsens) in the reforecasts after the removal of the corresponding bias. Small errors in storm-track intensity that are found in the northeastern North Pacific Ocean (Fig. 2e) are reduced by 30\%-50\% (Fig. 2g). Larger errors that are found over the North Atlantic Ocean and over land (Fig. 2e) are reduced by 


\section{All-Storm-Track Mean PV Intensity for 2003-2010}

(a) Reanalysis PV

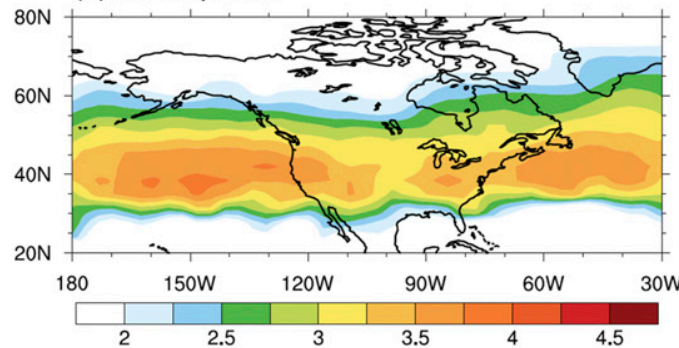

(b) PV Reforecast

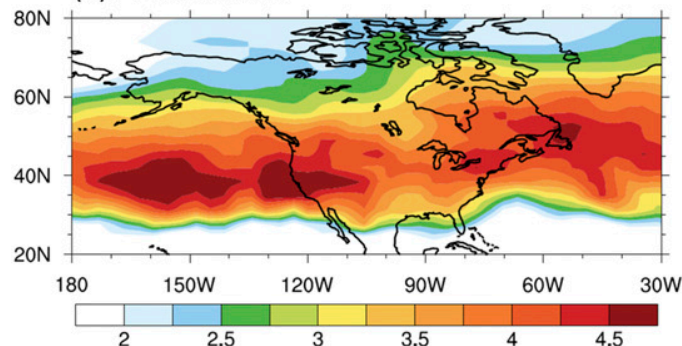

(c) Bias-corrected PV Reforecast

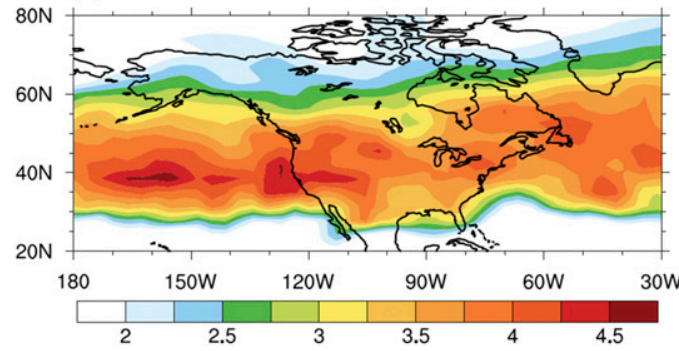

(d) SD of PV in Reanalysis

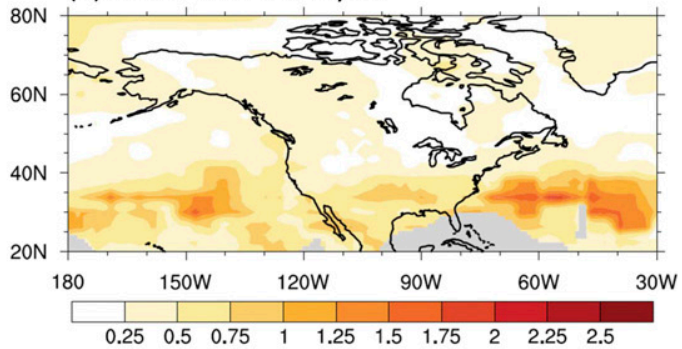

(e) RSR (colors) and RMSE of PV (contours)

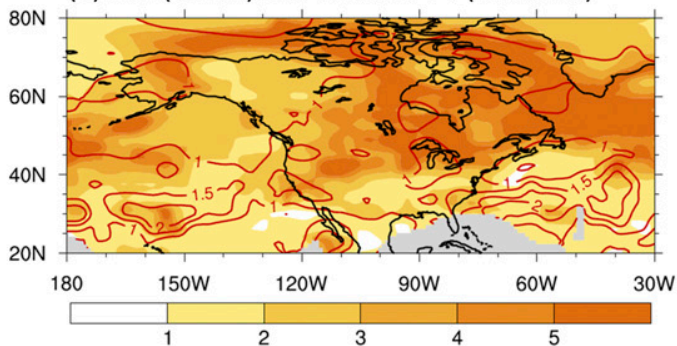

(f) RSR (colors) and RMSE of $\mathrm{PV}_{\mathrm{c}}$ (contours)

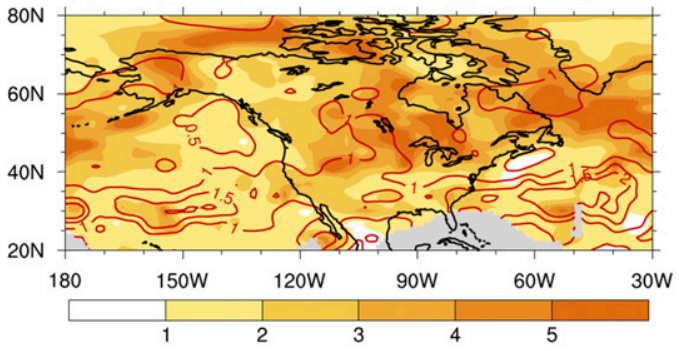

(g) \% Change in PV RMSE

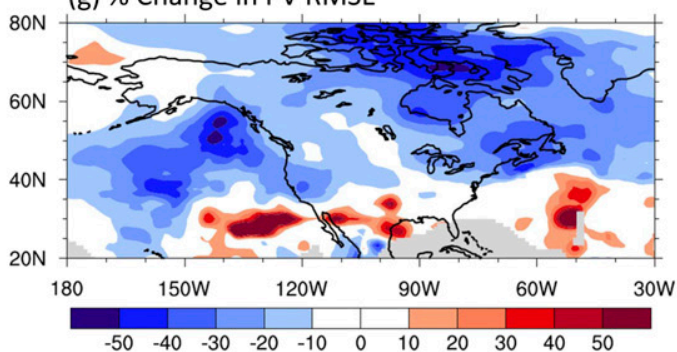

FIG. 2. Mean PV intensity of points along the all-storm tracks during DJF for the validation period 2003-10. (a) CFS reanalysis PV; (b) PV in weeks 3-4 reforecasts; and (c) bias-corrected PV ( $\left.\mathrm{PV}_{c}\right)$ in weeks 3-4 reforecasts. (d) Standard deviation (SD) of reanalysis PV; (e) RMSE of weeks 3-4 reforecast PV (contours at 0.5-PVU interval) and RSR (color shades; interval 1); (f) as in (e), but for the bias-corrected $\mathrm{PV}_{c}$; and (g) percent change in RMSE after PV bias is removed from reforecasts, shown at an interval of $10 \%$. RSR is the ratio of RMSE of reforecast PV to SD of reanalysis PV. In (a)-(d) intervals are at 0.25 PVU. Areas in (d)-(g) with less than 0.5 storms per $10^{6} \mathrm{~km}^{2}$ per month in CFSR are masked (gray shade).

$10 \%-30 \%$ in the midlatitudes and by as much as $50 \%$ in the high latitudes (Fig. 2g). Biases remain in areas over the oceans in the lower latitudes where the storm-track density is quite low ( $<1$ storm per unit area per month).
Because these errors are found outside of the main activity storm-track regions, they are not representative of characteristic midlatitude storm-track behavior and as such can be disregarded for the purposes of our study. 


\section{All-Storm Track Density Statistics for 2003-2010}
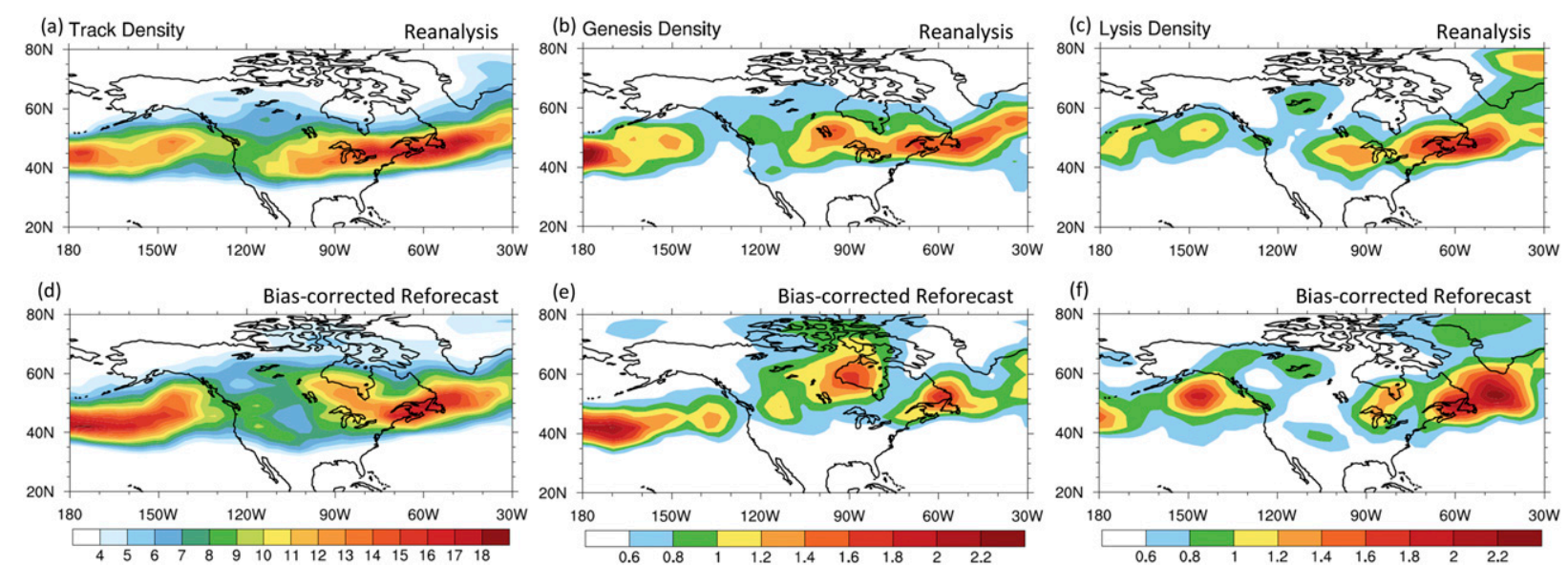

FIG. 3. Density statistics (storms per $10^{6} \mathrm{~km}^{2}$ per month) of NH all-storm tracks during DJF for the validation period 2003-10. (top) CFSR and (bottom) bias-corrected weeks 3-4 reforecasts. Shown are (a),(d) track, (b),(e) genesis, and (c),(f) lysis densities. Track densities are shown at intervals of 1 , while genesis and lysis densities are shown at intervals of 0.2 . Areas with less than 0.5 storms per $10^{6} \mathrm{~km}^{2}$ per month in CFSR are masked.

\section{b. Storm-track properties in the validation period 2003-10}

The all-storm-track density statistics that represent characteristic winter storm-track behavior in the reanalysis and in the bias-corrected weeks 3-4 reforecasts are presented in Fig. 3 for the validation period 2003-10. Note that by correcting the intensities, other statistics like cyclogenesis are also adjusted. For the reanalysis, the track density (Fig. 3a) and the genesis and lysis densities (Figs. 3b and $3 \mathrm{c}$, respectively) are similar to those from previous studies (e.g., Hoskins and Hodges 2002; Lukens et al. 2018). The zonally oriented Pacific storm track and the southwest-northeast-oriented North American-Atlantic (NAA) storm track are clearly highlighted in the track density, with the Rocky Mountains in western North America acting as a dynamic barrier between the two tracks (Brayshaw et al. 2009; Chang 2009). Regions of cyclogenesis (Fig. 3b) are found upstream of storm-track intensity maxima (see Fig. 2a), with a high number of cyclones developing over the central North Pacific Ocean. As well, many cyclones develop over land in central Canada, near the east coast of North America, and over the North Atlantic Ocean. High densities of cyclogenesis features near the east coast are representative of local nor'easter storms that tend to develop there in winter (Davis and Dolan 1993). Cyclolysis features in the reanalysis (Fig. 3c) are found in the downstream sectors of the storm tracks, particularly over the eastern North Pacific Ocean near the North American west coast and over the North Atlantic Ocean in the higher midlatitudes near the Canadian east coast. Over land, storms tend to dissipate in the northern United States near the Great Lakes.
The intensity bias correction is found to generally improve these features, and the results are presented in Figs. $3 \mathrm{~d}-\mathrm{f}$ that show the density statistics for the biascorrected reforecasts for 2003-10. The Pacific and NAA storm tracks in the track density bias-corrected reforecast (Fig. 3d) share similar spatial distributions to those in the reanalysis (see Fig. 3a), with the reforecast exhibiting a slightly higher concentration of cyclone activity in the North Pacific Ocean. The oceanic features shown in the reforecasts of genesis density (Fig. 3e) and lysis density (Fig. 3f) resemble those in the reanalysis, with differences in magnitude found in the genesis density in the North Atlantic Ocean and in the lysis density in the northeastern North Pacific Ocean.

Over land, the magnitudes of the density features between the reanalysis and bias-corrected reforecasts are similar, although the features in the reforecasts are displaced to the north and east. The displacements reveal regional discontinuities that remain in the reforecasts after the bias is removed, specifically in the track density in the west over the Rocky Mountains and in the genesis and lysis densities over eastern Canada near the Great Lakes. This is perhaps indicative of the differences between the model and the reanalysis, which would require further study.

\section{All-storm-track-related weather in the reforecasts}

Near-surface weather in North America is largely influenced by the development and intensification of extratropical cyclones. In this section, the weatherrelated features associated with the all-storm tracks 
will be examined to assess to what extent the reforecasts reproduce those observed in the reanalysis. If they do reproduce what is observed, it will imply that the information carried in the reforecasts of storm tracks could be useful for predictive aims.

In section 3 , after the $\mathrm{PV}_{320}$ intensity bias was computed and removed from the storm intensity reforecasts, the all-storm-track statistics were redone and a new set of tracks was obtained. In this section, the uncorrected reforecasts of surface winds and precipitation (i.e., the original values from the reforecasts) are related to the bias-corrected storm tracks discussed in section 3 . The resultant weather distributions are used to compute reforecast climatologies of winter weather associated with the all-storm tracks in North America. While the PV bias correction improves the results relative to the relation of uncorrected $\mathrm{PV}$ with uncorrected weather reforecasts (not shown), it is found that the bias of winds and precipitation also need to be removed to improve the results (more on this below). This is done by removing the base period (1983-2002) weather biases from the instantaneous all-storm winds and precipitation in the base period and validation period (2003-10).

As in the case for storm-track intensity, new climatologies of all-storm-track-related winds and precipitation are computed from the corrected fields. If the corrected precipitation rates (PR) associated with a storm at a particular time step fall below zero, then the precipitation rate at that grid point is set equal to zero, as is done in Zhu and Luo (2015). This occurred less than $10 \%$ of the time in CONUS. For winds, the $u$ and $v$ components are separately corrected, so the potential for a change in sign is allowed, and the wind speed is calculated after the components have been corrected. We have found that the bias correction of wind components yields a lower RMSE than the more typical correction of wind speed (not shown; e.g., Sweeney et al. 2013; Holman et al. 2017).

\section{a. Near-surface winds}

In Lukens et al. (2018), the CFSR winds in the model's hybrid level 1 (H1) were used to represent the near surface winds. In this study, for both CFSR and CFSRR we use the 1000-hPa winds as a proxy of the near-surface winds (mostly valid except over high topography). The reason is that the CFSRR H1 winds exhibit a yet unexplained behavior north of $30^{\circ} \mathrm{N}$. Figure 4 shows that while for CFSR latitudinal wind profiles at $1000 \mathrm{hPa}$ and $\mathrm{H} 1$ (curves in red) remain close to each other, the CFSRR winds at level H1 exhibit a substantial departure from the 1000-hPa winds (profiles in blue). This behavior is observed at all longitudes for all years in the period and led to inconsistent results. While bias

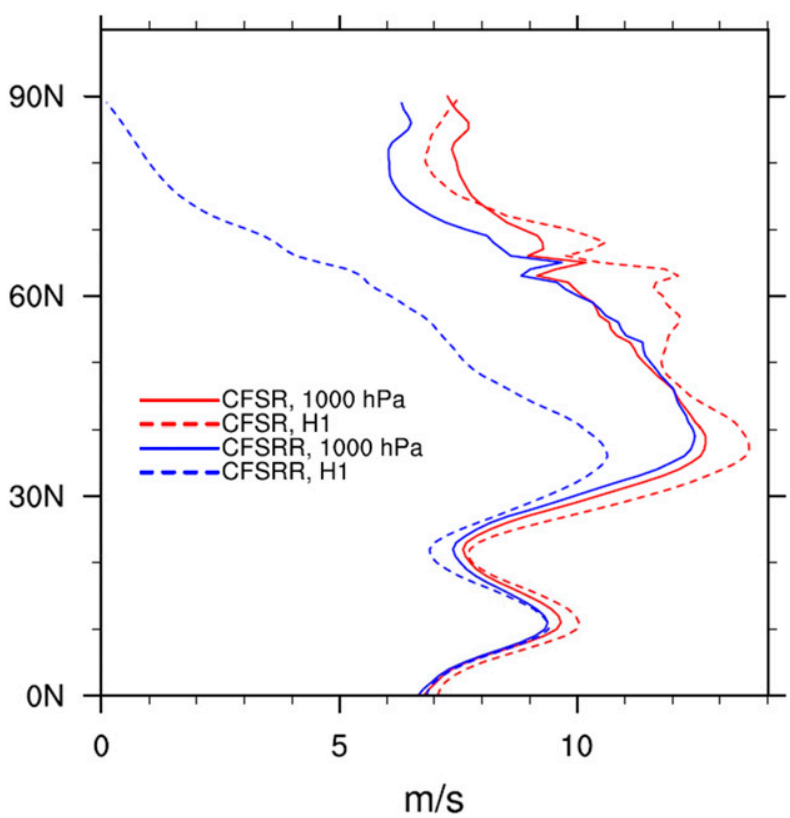

FIG. 4. Latitude vs climatological wind speed $\left(\mathrm{m} \mathrm{s}^{-1}\right)$ averaged along the longitude $170^{\circ} \mathrm{W}$ during DJF for $1983-2010$. Solid lines indicate $1000-\mathrm{hPa}$ winds, while dashed lines indicate winds on the hybrid level 1 surface. CFSR is shown in red colors, and the weeks 3-4 reforecasts are shown in blue colors.

correction removed a large portion of the errors, we opted for using winds at $1000 \mathrm{hPa}$. We are unaware of any previous study documenting this behavior in CFSRR, and understanding its reasons is outside the scope of this article.

We examine the relation of winds on the $1000-\mathrm{hPa}$ surface to the winter all-storm tracks. Figure 5 presents the time average of all the winds found within $5^{\circ}$ of each point along every cyclone trajectory that shape the all-storm tracks for the base period 1983-2002. In general, near-surface winds are stronger over the oceans than land due in part to a lower value of surface drag over water (Holton 2004). Storm tracks act to enhance the relative strength of the winds in any region (ocean or land), in particular where the storm tracks are more intense (see Lukens et al. 2018, their Fig. 7). The reanalysis of all-storm winds (Fig. 5a) reflects these relations, exhibiting amplified wind speeds over the oceans and North America. Specifically, local maxima are found in the central North Pacific Ocean and across the North Atlantic Ocean. Over land, the strongest winds are found in eastern North America between the Rocky Mountains and the U.S. East Coast.

We next evaluate to what extent the reforecasts represent storm-track-related winds. The uncorrected wind reforecasts related to the bias-corrected storm tracks 


\section{Winds related to PV in All-Storm Tracks for 1983-2002}

(a) V(PV) in Reanalysis

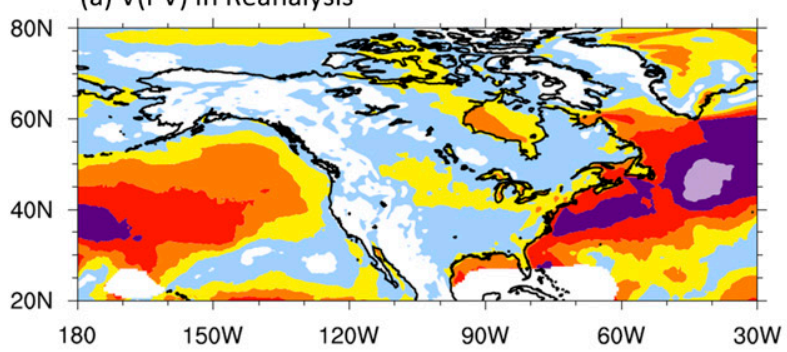

(b) $V\left(P V_{c}\right)$ in Reforecasts

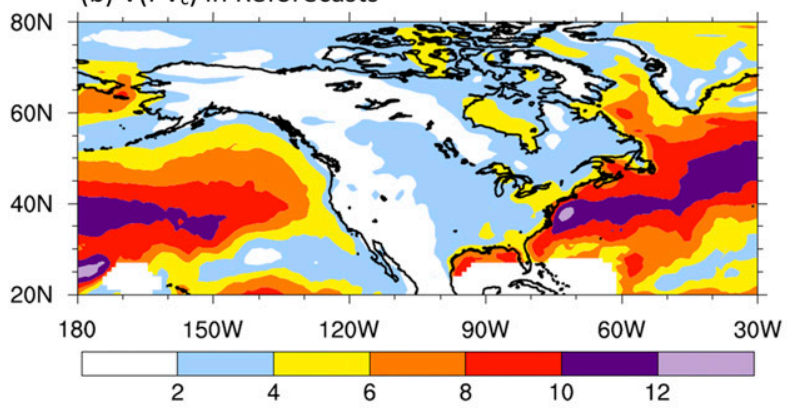

(c) Bias in Winds

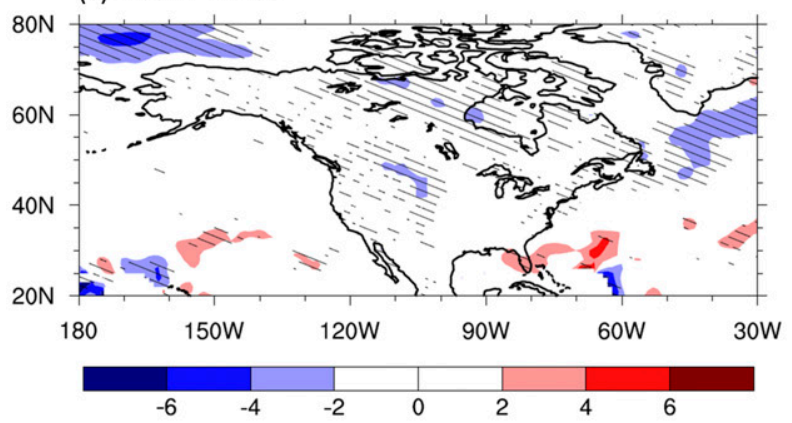

(d) $V_{c}\left(P V_{c}\right)$ in Reforecasts

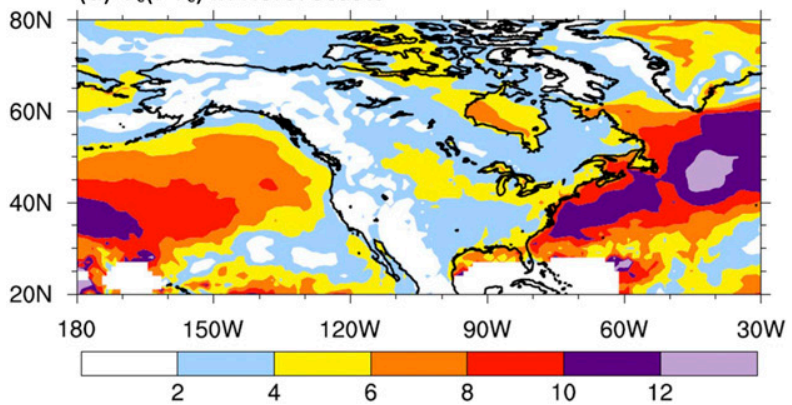

FIG. 5. Mean all-storm-track-related wind speed on the 1000-hPa surface during DJF for the base period 1983-2002. (a) CFS reanalysis wind speed $V$ associated with reanalysis PV; (b) weeks 3-4 reforecast wind speed associated with reforecast $\mathrm{PV}_{c}$; (c) wind bias (reforecast minus reanalysis), where hatched regions are statistically significant $(p<0.05)$; and (d) bias-corrected weeks 3-4 reforecast wind speed $V_{c}$ associated with reforecast $\mathrm{PV}_{c}$. The contour interval for all panels is $2 \mathrm{~m} \mathrm{~s}^{-1}$. Areas with less than 0.5 storms per $10^{6} \mathrm{~km}^{2}$ per month in CFSR are masked.
(Fig. 5b) are found to represent well the all-storm-trackrelated wind speeds in the midlatitudes for 1983-2002. However, following Eq. (3), small yet statistically significant negative biases are found in the storm-track regions of the wind reforecasts (Fig. 5c), specifically in the northeastern sector of the North Atlantic Ocean and near the Rocky Mountains over land. A bias correction is performed where the local systematic error in the near-surface wind field is removed from the all-storm wind reforecasts. Notably, the removal of the wind bias for 1983-2002 yields a corrected reforecast for the base period (Fig. 5d) that bears a closer resemblance to the reanalysis.

We test the validity of the approach as it pertains to allstorm-track-related winds by removing the average systematic error for 1983-2002 from each of the reforecasts for 2003-10 and recalculating the related storm-track near-surface winds. The results are presented in Fig. 6. Figure 6a shows that the all-storm winds in the reanalysis for the validation period 2003-10 are slightly stronger than those for the base period (see Fig. 5a), particularly in the western North Atlantic Ocean. As is the case for the base period wind reforecasts, the reforecasts for the validation period (Fig. 6b) are similar to the all-storm-trackrelated winds in the reanalysis, with weaker wind speeds found in the North Atlantic Ocean and eastern North America. The wind bias for 1983-2002 (see Fig. 5c) is then removed from the reforecasts of all-storm-track-related winds for 2003-10, and the resultant bias-corrected wind reforecast is presented in Fig. 6c. Some improvement is found over the oceans as well as over land in the eastern United States.

A statistical comparison of the all-storm wind reforecasts before and after the bias correction shows that the reforecasts already closely match the reanalysis (Figs. 6d-g). As in the case of the PV SD (see Fig. 3d), the SD of all-storm winds in the reanalysis is highest over the oceans in the lower midlatitudes (Fig. 6d). The RMSE of uncorrected all-storm winds (Fig. 6e, contours) is larger than the SD in those regions as well as in the northeast ocean basins and over land in eastern North America. The corresponding ratio RSR of allstorm winds is generally low (Fig. 6e, color shades), particularly in the lower midlatitudes where the SD is highest, suggesting that the uncorrected reforecasts already somewhat capture the variability in all-stormtrack-related winds.

The all-storm wind reforecasts further improve after the base period wind bias is removed, as evidenced by the reduced RMSE of the bias-corrected reforecast winds (Fig. 6f, contours) and the low values of the corresponding RSR (Fig. 6f, color shades). Areas of improvement are further highlighted by negative values 


\section{Winds related to PV in All-Storm Tracks for 2003-2010}

(a) V(PV) in Reanalysis

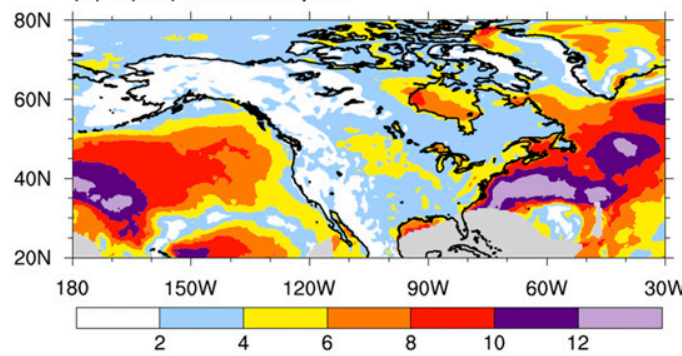

(b) $\mathrm{V}\left(\mathrm{PV} \mathrm{V}_{\mathrm{c}}\right)$ in Reforecasts

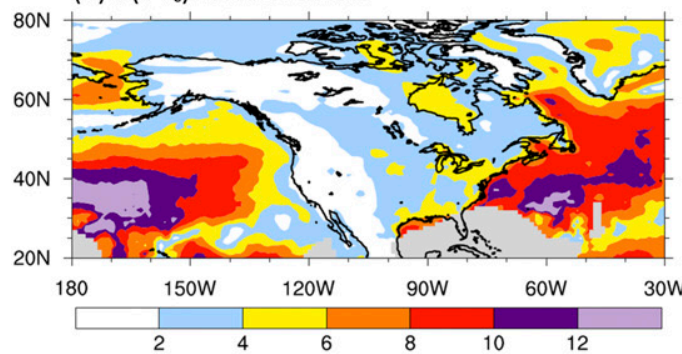

(c) $V_{c}\left(P V_{c}\right)$ in Reforecasts

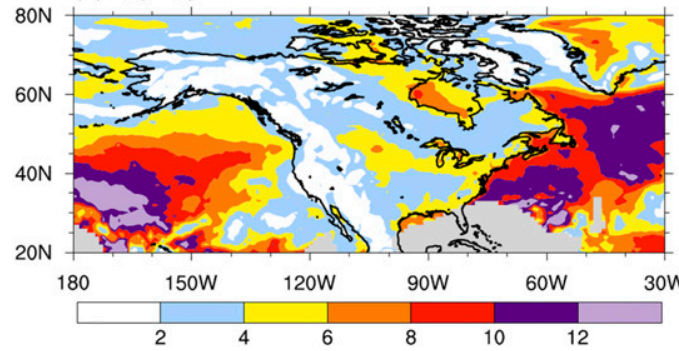

(d) SD of V(PV) in Reanalysis

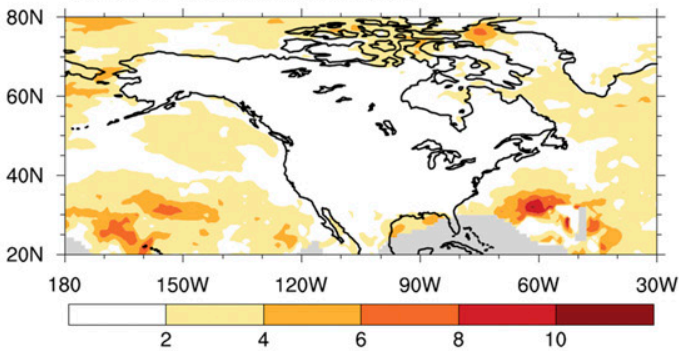

(e) RSR (colors) and RMSE of V(PV $)$ (contours)

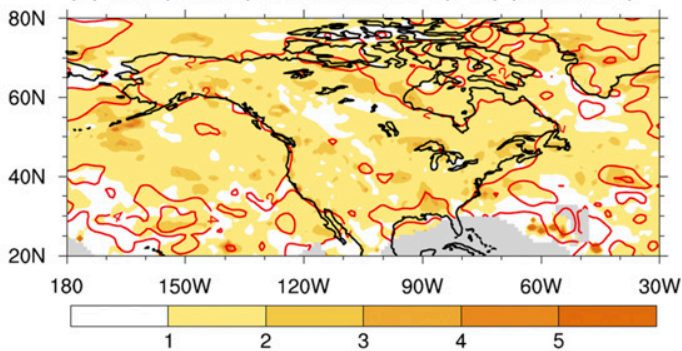

(f) RSR (colors) and RMSE of $\mathrm{V}_{c}\left(\mathrm{PV}_{\mathrm{c}}\right)$ (contours)

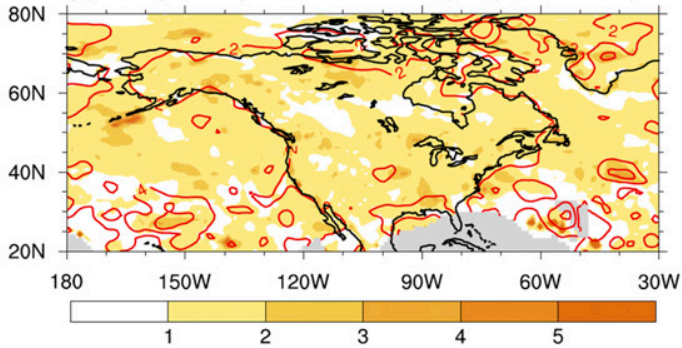

(g) \% Change in Wind RMSE

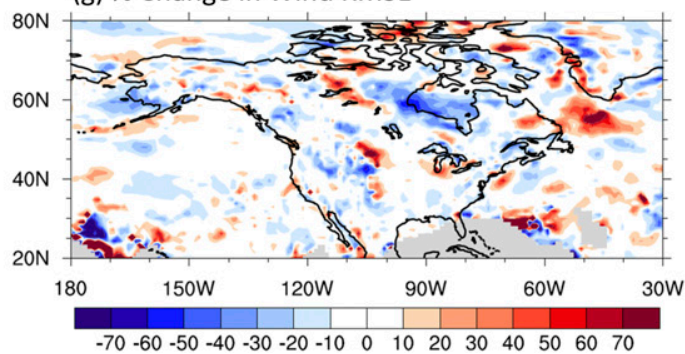

FIG. 6. Mean all-storm-track-related wind speed on the 1000-hPa surface during DJF for the validation period 2003-10. (a) CFS reanalysis wind speed $V$ associated with reanalysis PV; (b) weeks $3-4$ reforecast wind speed associated with reforecast $\mathrm{PV}_{c}$; and (c) bias-corrected weeks 3-4 reforecast wind speed $V_{c}$ associated with reforecast $\mathrm{PV}_{c}$. (d) Standard deviation (SD) of reanalysis $V(\mathrm{PV})$; (e) RMSE of weeks 3-4 reforecast $V\left(\mathrm{PV}_{c}\right)$ (contours at $2 \mathrm{~m} \mathrm{~s}^{-1}$ interval) and RSR (color shades; interval 1); (f) as in (e), but for the bias-corrected $V_{c}\left(\mathrm{PV}_{c}\right)$; and $(\mathrm{g})$ percent change in RMSE after wind bias is removed from reforecasts, shown at an interval of $10 \%$. RSR is the ratio of RMSE of reforecast $V\left(\mathrm{PV}_{c}\right)$ to SD of reanalysis $V(\mathrm{PV})$. In (a)-(d) intervals are $2 \mathrm{~m} \mathrm{~s}^{-1}$. Areas with less than 0.5 storms per $10^{6} \mathrm{~km}^{2}$ per month in CFSR are masked (gray shade).

in the change in the wind RMSE (Fig. 6g). The small error in all-storm wind speed is reduced on average by about $12 \%$ in the storm-track regions. Specifically, decreased errors are found in the lower midlatitudes over the eastern North Pacific and western North Atlantic Oceans as well as in the eastern United States. Additionally, the removal of the 1983-2002 wind bias from the 2003-10 reforecasts reduces the error in 
Precipitation related to PV in All-Storm Tracks

\section{for 1983-2002}

(a) CPC PR(PV) in Reanalysis

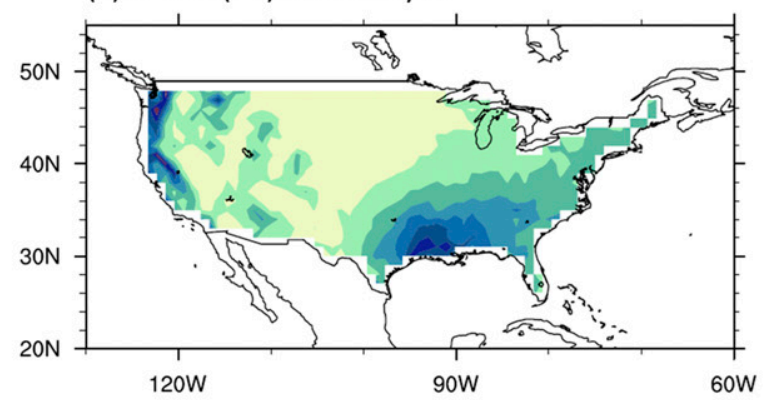

(b) $P R\left(P V_{c}\right)$ in Reforecasts

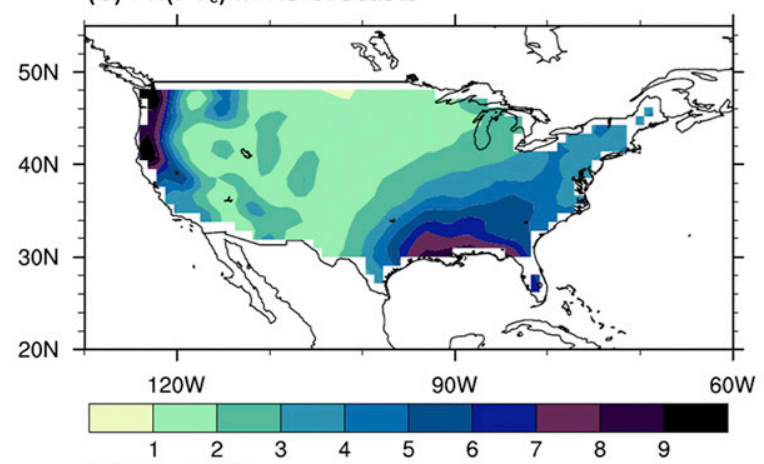

(c) Bias in PR

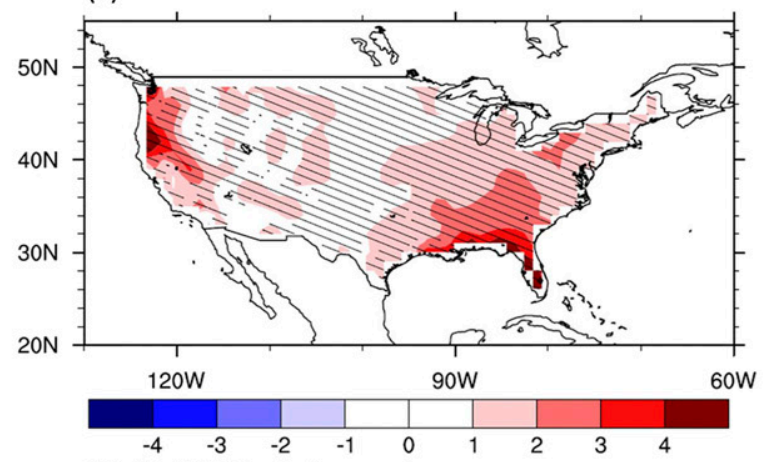

(d) $P R_{c}\left(P V_{c}\right)$ in Reforecasts

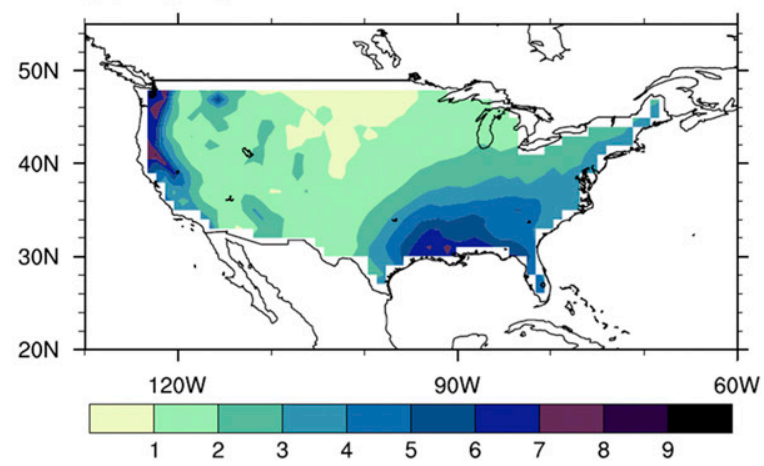

FIG. 7. Mean all-storm-track-related daily PR during DJF for the base period 1983-2002 in the CONUS. (a) CPC gaugebased analysis PR associated with reanalysis PV; (b) weeks 3-4 reforecast $\mathrm{PR}$ associated with reforecast $\mathrm{PV}_{c} ;(\mathrm{c}) \mathrm{PR}$ bias (reforecast estimation in the high latitudes outside of the main regions of storm activity. In summary, the findings indicate that the CFS weeks 3-4 reforecasts already contain useful information for the prediction of near-surface storm winds at weeks 3-4 time scales, with the bias correction providing additional minor improvements.

\section{b. Precipitation}

The relation of winter precipitation at the surface in CONUS to the all-storm tracks is examined next. The time average of all precipitation in CONUS that is found within $12^{\circ}$ of each point along every cyclone trajectory that shape the all-storm tracks for the base period 1983-2002 is presented in Fig. 7. In the CPC gauge-based daily precipitation analysis (Fig. 7a), precipitation rates associated with the all-storm tracks are highest near the North American west coast where they exceed $7 \mathrm{~mm} \mathrm{day}^{-1}$ and in the southeastern United States where they reach $6 \mathrm{~mm} \mathrm{day}^{-1}$.

In the corresponding uncorrected weeks 3-4 reforecast (Fig. 7b), precipitation related to the bias-corrected allstorm tracks is overestimated. Specifically, the uncorrected reforecasts tend to overestimate precipitation in the eastern United States and near the west coast. This is more clearly seen in Fig. 7c that highlights statistically significant biases in the reforecasts for the base period, following Eq. (3). The removal of the bias yields the corrected all-storm precipitation associated with the biascorrected storm tracks for 1983-2002 (Fig. 7d). As in the case of winds, the bias-corrected precipitation reforecasts better correspond with observations.

The approach is validated for the period 2003-10, with the time average of winter precipitation over CONUS found within $12^{\circ}$ of all storm centers in the all-storm tracks being presented in Fig. 8. The CPC analysis for the validation period (Fig. 8a) depicts a similar precipitation pattern to that for the base period (see Fig. 7a), with maxima found near the west coast of North America and in the southeastern United States. The uncorrected reforecast precipitation for 2003-10 (Fig. 8b) exhibits large overestimations in these areas. The removal of the base period bias (see Fig. 7c) from the uncorrected reforecasts for the validation period yields improvements in the 2003-10 precipitation reforecasts (Fig. 8c). The precipitation intensity in the bias-corrected reforecasts

minus CPC analysis), where hatched regions are statistically significant $(p<0.05)$; and (d) bias-corrected weeks 3-4 reforecast PR $\left(\mathrm{PR}_{c}\right)$ associated with reforecast $\mathrm{PV}_{c}$. The contour interval for all panels is $1 \mathrm{~mm}$ day $^{-1}$. Areas outside CONUS are masked. 


\section{Precipitation related to PV in All-Storm Tracks for 2003-2010}

(a) $P R(P V)$ in Reanalysis

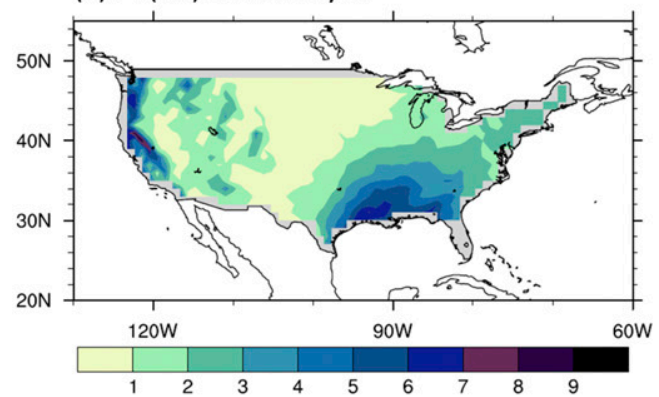

(b) $P R\left(P V_{c}\right)$ in Reforecasts

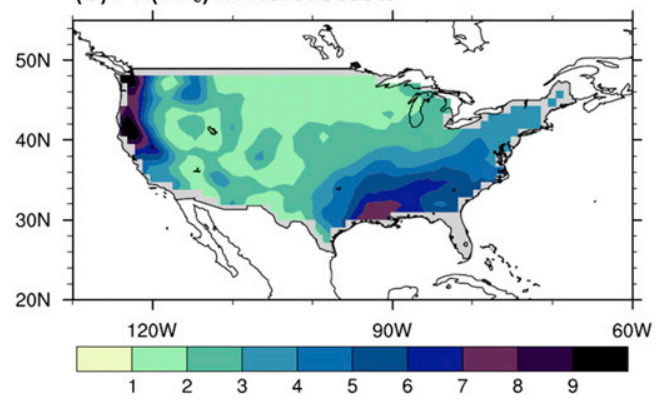

(c) $P R_{c}\left(P V_{c}\right)$ in Reforecasts

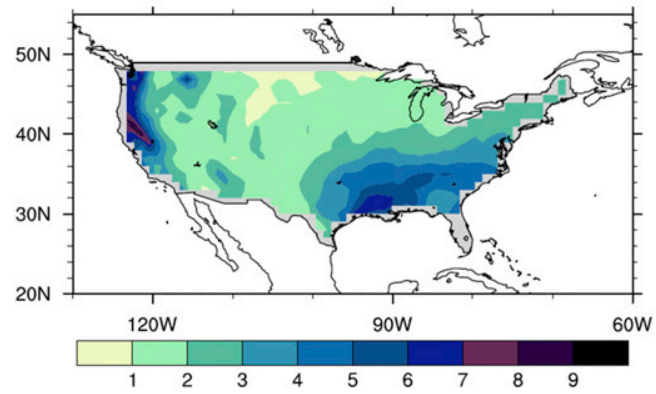

(d) SD of PR(PV) in Reanalysis

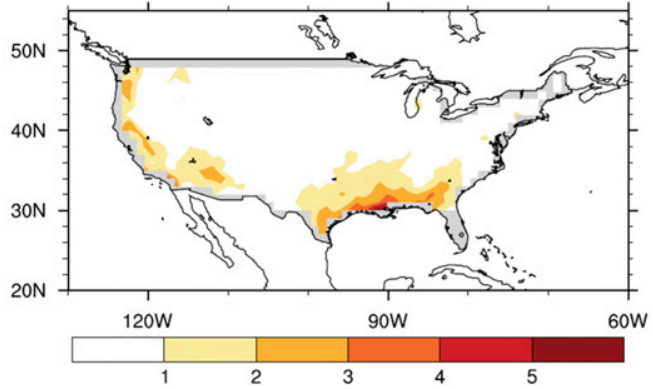

(e) RSR (colors) and RMSE of $\mathrm{PR}\left(\mathrm{PV}_{\mathrm{c}}\right)$ (contours)

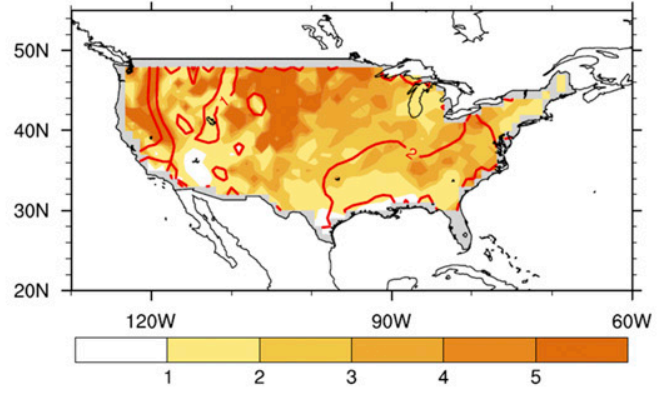

(f) RSR (colors) and RMSE of $P R_{c}\left(P V_{c}\right)$ (contours)

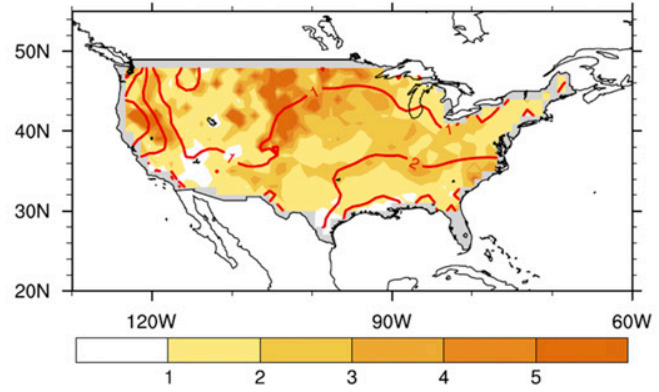

(g) \% Change in PR RMSE

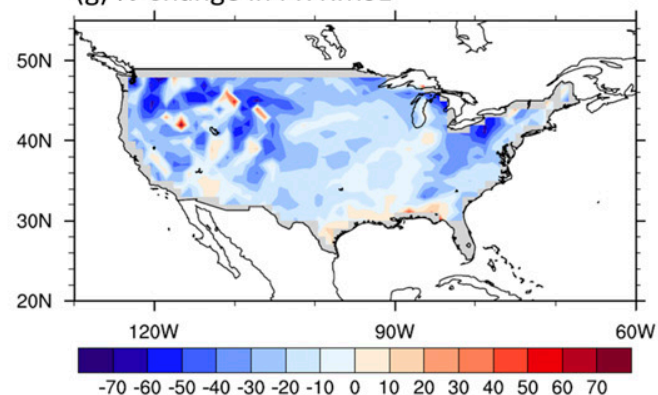

FIG. 8. Mean all-storm-track-related daily PR during DJF for the validation period 2003-10 in the CONUS. (a) CPC gauge-based analysis PR associated with reanalysis PV; (b) weeks 3-4 reforecast PR associated with reforecast $\mathrm{PV}_{c}$; (c) bias-corrected weeks 3-4 reforecast $\mathrm{PR}\left(\mathrm{PR}_{c}\right)$ associated with reforecast $\mathrm{PV}_{c}$. (d) SD of reanalysis $\mathrm{PR}(\mathrm{PV})$; (e) RMSE of weeks 3-4 reforecast $\mathrm{PR}\left(\mathrm{PV}_{c}\right)$ (contours at $1 \mathrm{~mm}^{-1}{ }^{-1}$ interval) and RSR (color shades; interval 1); (f) as in (e), but for the bias-corrected $\mathrm{PR}_{c}\left(\mathrm{PV}_{c}\right) ;(\mathrm{g})$ percent change in RMSE after PR bias is removed from reforecasts, shown at an interval of $10 \%$. RSR is the ratio of RMSE of reforecast $\mathrm{PR}\left(\mathrm{PV}_{c}\right)$ to SD of reanalysis $\mathrm{PR}(\mathrm{PV})$. Intervals in (a)-(d) are shown at $1 \mathrm{~mm}^{-1 a y}{ }^{-1}$. Areas in CONUS with missing values and less than 0.5 storms per $10^{6} \mathrm{~km}^{2}$ per month in CFSR are masked (gray shade). 
is reduced near the west coast and in the eastern United States. The improvements are reflected in Figs. 8d-g that describe the performance of CFSRR before and after the bias correction. The standard deviation of precipitation in the reanalysis (Fig. 8d) is shown to be highest in the western and southeastern United States where the precipitation rates are highest. Likewise, the uncorrected precipitation RMSE (Fig. 8e, contours) is largest in these regions. However, in the eastern United States the corresponding ratio RSR (Fig. 8e, color shades) is lower where the precipitation rates are high and higher where the precipitation rates are low. The low RSR in regions with high precipitation rates suggest the usability of the reforecasts without the correction. After the base period precipitation bias is removed from the validation period reforecasts, the RMSE is reduced (Fig. 8f, contours) and gets closer to the magnitude of the standard deviation of reanalysis precipitation (see Fig. 8d). This is exemplified in the reduced RSR of the bias-corrected reforecasts (Fig. 8f, color shades) and suggests that the bias-corrected reforecasts better depict the general variability in precipitation in CONUS, although the correction appears to have little to no effect in regions with low RSR. The percent change in RMSE for precipitation (Fig. 8g) supports this finding, as it displays large reductions in error in regions with lower precipitation rates and smaller decreases in areas with high precipitation rates. Further, the error in estimation is found to decrease by about $25 \%$ on average in CONUS, although large biases remain in the western and southeastern United States, where the all-storm precipitation rates are highest. Overall, the findings suggest that the removal of the precipitation biases from the reforecasts lead to RSR decreases in the storm tracks, improving the representation of the observed variability in all-storm-track-related precipitation in the CFS weeks 3-4 reforecasts.

\section{Reforecasts of strong-storm tracks and related weather}

This section will discuss a subset of all storms: those that achieve high PV intensities and shape what are called "strong-storm tracks." Strong storms have the potential to produce high winds and heavy precipitation that can induce transportation interruptions, higher demands for power and emergency supplies, and an increased risk of damages and casualties (Kunkel et al. 2013; Wang et al. 2017). Moreover, strong-storm tracks have been found to have a significant imprint on winter weather in North America (Lukens et al. 2018).

Following a similar approach to that discussed in section 2 and in Lukens et al. (2018), strong-storm tracks
TABLE 2. Values of average $\mathrm{PV}_{320}$ maximum $\left(\overline{\mathrm{PV}}_{x}\right)$ and $\mathrm{PV} x \mathrm{SD}$ used to compute strong-storm threshold $T_{\text {str }}$ for the reanalysis, weeks 3-4 reforecasts, and bias-corrected weeks 3-4 reforecasts. Thresholds are obtained from all storms in the Pacific (PAC) and North American-Atlantic (NAA) storm-track regions in the validation period 2003-10. Units are PVU.

\begin{tabular}{lccc}
\hline \hline \multicolumn{1}{c}{ PAC, NAA 2003-10 } & $\overline{\mathrm{PV}}_{x}$ & $\left(\mathrm{PV}_{x}\right)_{\mathrm{SD}}$ & $T_{\mathrm{str}}$ \\
\hline Reanalysis & 3.8 & 1.1 & 4.9 \\
Reforecasts & 4.9 & 1.6 & 6.5 \\
Bias-corrected reforecasts & 4.6 & 1.5 & 6.1 \\
\hline
\end{tabular}

are shaped by storms with maximum PV intensities that exceed a threshold of:

$$
T_{\text {str }}=\overline{\mathrm{PV}}_{x}+1 \times\left(\mathrm{PV}_{x}\right)_{\mathrm{SD}},
$$

where $T_{\text {str }}$ refers to the threshold for strong storms and all other terms were defined for Eq. (1). The $T_{\text {str }}$ is calculated separately for the Pacific and NAA storm tracks for the validation period 2003-10 only. The values used to compute $T_{\mathrm{str}}$ are the same for both storm tracks and are shown for the reanalysis and reforecasts in Table 2. Differences in $T_{\text {str }}$ between the datasets are due to differences in $\overline{\mathrm{PV}}_{x}$ and $\left(\mathrm{PV}_{x}\right)_{\mathrm{SD}}$, where the higher values in the reforecasts yield higher $T_{\text {str }}$ thresholds. Following Eq. (4), a strong storm that develops in either the Pacific or NAA storm track region in the reanalysis for 2003-10 must achieve a maximum intensity of 4.9 PVU or greater (Table 2). The overestimation of all-storm-track intensity found in the uncorrected reforecasts (section 3) gives rise to a higher strong-storm threshold value of 6.5 PVU for storms. This value decreases to 6.1 PVU after the intensity bias is removed, reflecting the improvement in the reforecasts also discussed in section 3.

Strong storms in the reanalysis are found to represent about $15 \%$ of all storms that develop in the Pacific and NAA storm-track regions in 2003-10. As in CFSR, strong storms in the uncorrected and bias-corrected reforecasts are found to represent about $15 \%$ of all storms that develop in either region, suggesting that the reforecasts capture the relative distribution of strong storms in winter despite overestimations in storm $\mathrm{PV}_{320}$ intensity.

Characteristics of strong-storm-track behavior are presented as density statistics in Fig. 9. The reanalysis strong-storm densities (Figs. 9a-c) resemble those for the all-storm tracks (see Figs. 3a-c) and correspond well with those presented in Lukens et al. (2018). The track density (Fig. 9a) exhibits high concentrations of strongstorm activity throughout the Pacific and NAA stormtrack regions, with the highest concentrations found over the North Atlantic Ocean. Strong-storm cyclogenesis features (Fig. 9b) are found upstream of track density 


\section{Strong-Storm Track Density Statistics for 2003-2010}
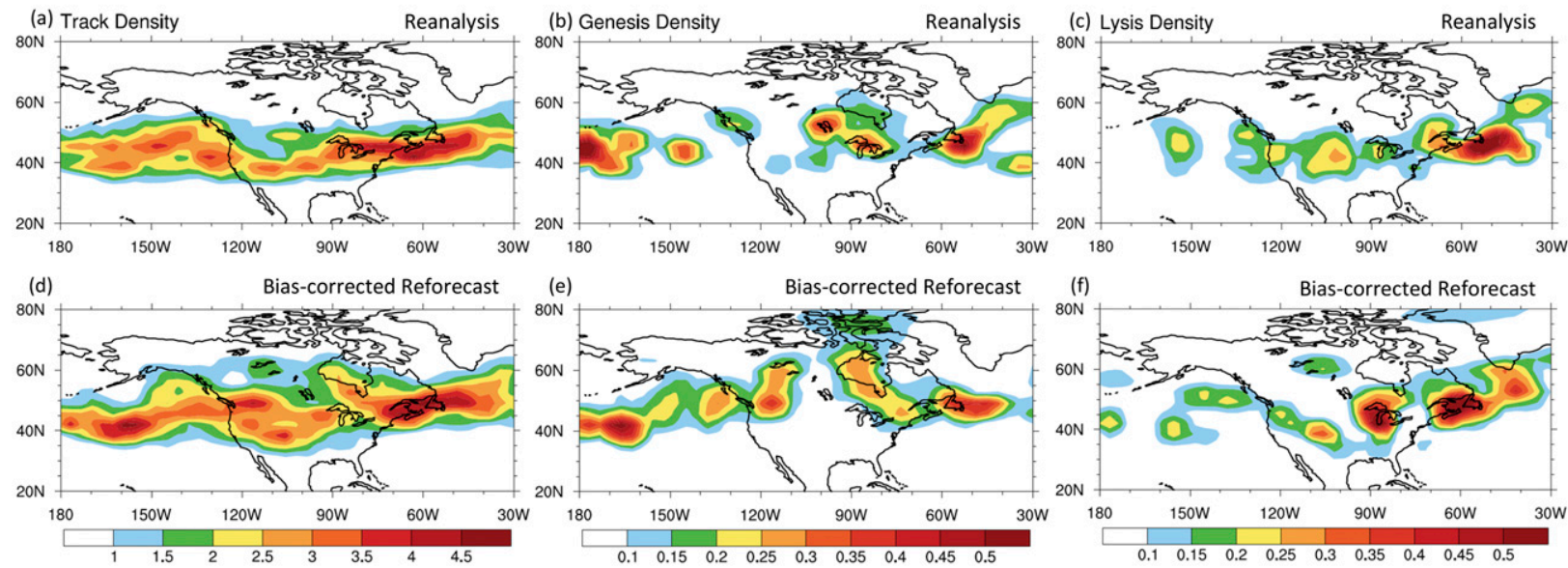

FIG. 9. Density statistics of NH strong-storm tracks during DJF for the validation period 2003-10. (top) CFSR and (bias) bias-corrected weeks 3-4 reforecasts. Shown are (a),(d) track, (b),(e) genesis, and (c),(f) lysis densities. Units for all panels are storms per $10^{6} \mathrm{~km}^{2}$ per month. Track densities are shown at intervals of 0.5, while genesis and lysis densities are shown at intervals of 0.05 . Areas where strong storms are not found and where there are less than 0.5 storms per $10^{6} \mathrm{~km}^{2}$ per month in CFSR are masked.

maxima while cyclolysis regions are found downstream (Fig. 9c).

The PV intensity bias correction in the all-storm tracks (section 3) is found to generally improve the strong-storm density features in the reforecasts, and the results are presented in Figs. 9d-f. The strong-stormtrack density in the bias-corrected reforecasts (Fig. 9d) shares similar spatial distributions to that of the reanalysis (see Fig. 9a), with the reforecasts displaying higher concentrations of storm activity over the eastern North Pacific Ocean and over land. Over the oceans, the cyclogenesis and cyclolysis features in the bias-corrected reforecasts (Figs. 9e and 9f, respectively) resemble those of the reanalysis, although regional discontinuities remain in the reforecasts after the all-storm intensity bias is removed. This is particularly evident over land 1) in western (eastern) Canada where cyclogenesis features in the reforecasts are amplified (dampened) and displaced to the east and 2) in the western United States and the Great Lakes region where cyclolysis features in the reforecasts are amplified and displaced to the south.

\section{a. Winds and precipitation}

In this section, the relation between strong-storm tracks and winter weather variables in the weeks 3-4 reforecasts for the validation period (2003-10) is assessed. This is done in the reforecasts by relating the uncorrected winds and precipitation to the strong-storm tracks that are a subset of the "bias-corrected" all-storm tracks. Further, we relate the bias-corrected weather reforecasts (section 4) to the bias-corrected strong-storm tracks to examine the effects of the bias correction of all-storm weather on the reforecasts of strong-storm weather.

Near-surface winds associated with the strong-storm tracks in the validation period $2003-10$ are presented in Fig. 10. The strong-storm-track-related winds in the reanalysis (Fig. 10a) are found to be most intense over the oceans and in eastern North America, corresponding with the findings of Lukens et al. (2018). Moreover, they are stronger on average than the all-storm-track-related winds (see Fig. 6a), specifically in the western North Atlantic Ocean where deep convective heating tends to add to the local baroclinicity and invigorate strong storms (Chang 2009; Lukens et al. 2018). The results presented here using PV to track cyclones are consistent with the findings from other studies that identify storms using sea level pressure (e.g., Leckebusch et al. 2008; Booth et al. 2015). Those studies found that strong surface winds are generally found to the south and southeast of the centers of storms that produce strong winds. This study shows that on average in winter, the strongest near-surface winds associated with cyclones (Fig. 10a) are often found south of strong-storm (or cyclone) track density maxima (see Fig. 9a).

As in the case of all-storm winds, the uncorrected reforecast of strong-storm winds (Fig. 10b) exhibit similar patterns to the reanalysis in Fig. 10a, with slightly weaker wind speeds found in the northeastern North Pacific and western North Atlantic Oceans. The biascorrected winds related to the strong-storm tracks are depicted in Fig. 10c. Improvements are found in the northeastern North Atlantic Ocean and in eastern 


\section{Winds related to PV in Strong-Storm Tracks for 2003-2010}

(a) V(PV) in Reanalysis

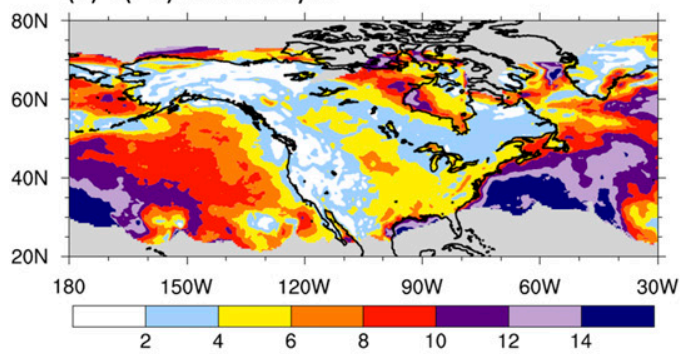

(b) $V\left(P V_{c}\right)$ in Reforecasts

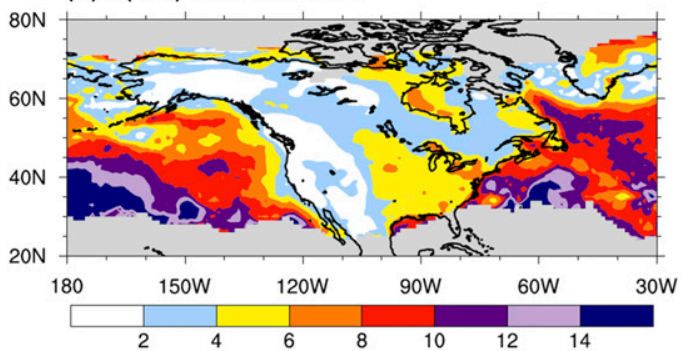

(c) $V_{c}\left(P V_{c}\right)$ in Reforecasts

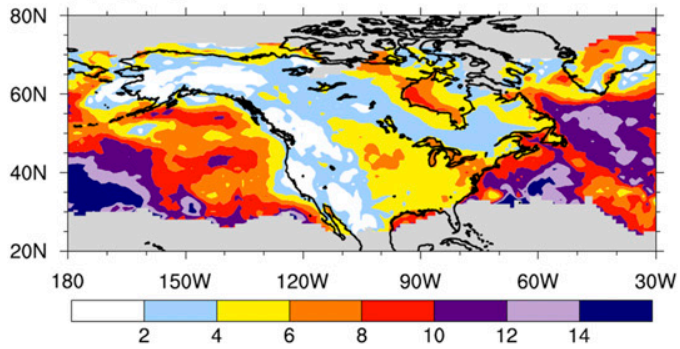

(d) SD of V(PV) in Reanalysis

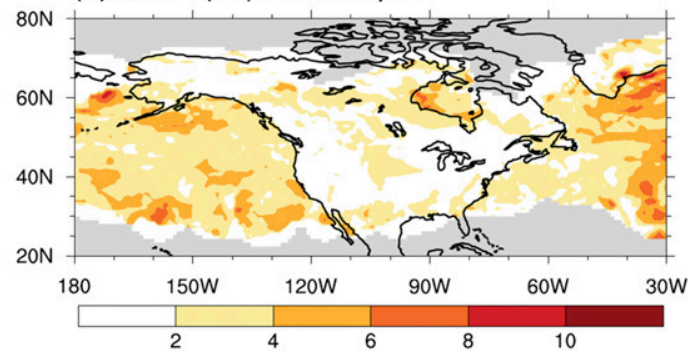

(e) RSR (colors) and RMSE for V(PV $\left.{ }_{c}\right)$ (contours)

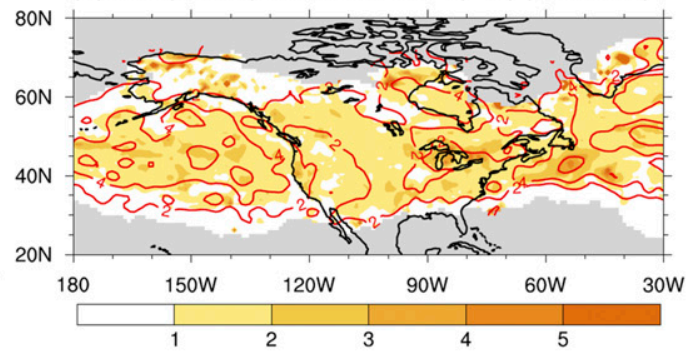

(f) RSR (colors) and RMSE for $\mathrm{V}_{\mathrm{c}}\left(\mathrm{PV}_{\mathrm{c}}\right)$ (contours)

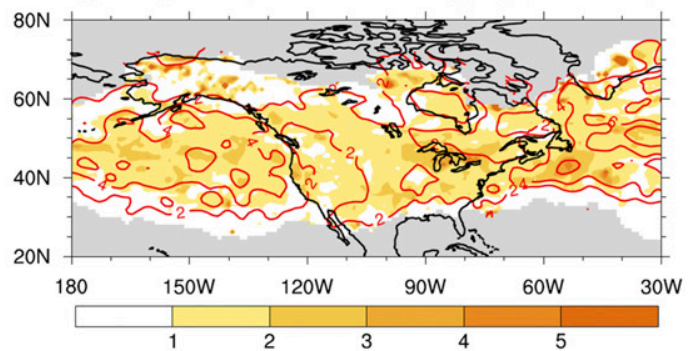

(g) \% Change in Wind RMSE

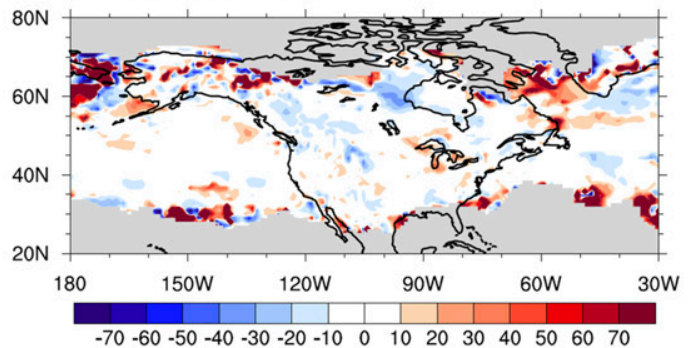

FIG. 10. Mean strong-storm-track-related wind speed on the 1000-hPa surface during DJF for the validation period 2003-10. (a) CFS reanalysis wind speed $V$ associated with reanalysis PV with $T_{\text {str }}=4.9$ PVU; (b) weeks 3-4 reforecast wind speed associated with reforecast $\mathrm{PV}_{c}$ with $T_{\text {str }}=6.1 \mathrm{PVU}$; (c) bias-corrected weeks 3-4 reforecast wind speed $V_{c}$ associated with reforecast $\mathrm{PV}_{c}$ with $T_{\text {str }}=6.1 \mathrm{PVU}$. (d) SD of reanalysis $V(\mathrm{PV})$; (e) RMSE of weeks 3-4 reforecast $V\left(\mathrm{PV}_{c}\right)$ (contours at $2 \mathrm{~m} \mathrm{~s}^{-1}$ interval) and RSR (color shades; interval 1); (f) as in (e), but for the bias-corrected $V_{c}\left(\mathrm{PV}_{c}\right)$; and $(\mathrm{g})$ percent change in RMSE after all-storm wind bias is removed from reforecasts, shown at an interval of $10 \%$. RSR is the ratio of RMSE of reforecast $V\left(\mathrm{PV}_{c}\right)$ to SD of reanalysis $V(\mathrm{PV})$. In (a)-(d) intervals are $2 \mathrm{~m} \mathrm{~s}^{-1}$. Areas with less than 0.5 storms per $10^{6} \mathrm{~km}^{2}$ per month in CFSR and where strong storms are not found are masked (gray shade).

North America. Additional improvements are found at high latitudes over Canada near the Hudson Bay.

Figures $10 \mathrm{~d}-\mathrm{g}$ present statistics of the strong-storm-track winds. The SD of the reanalysis strong-storm-track-related winds is relatively high over the North Pacific and central North Atlantic Oceans (Fig. 10d). Similarly, large RMSE values in the uncorrected strong-storm winds (Fig. 10e, contours) are found over water, in particular 
over the northeastern North Atlantic Ocean. Smaller errors are found over land in eastern North America. The ratio RSR for the uncorrected reforecasts (Fig. 10e, color shades) is generally low in the storm-track regions, indicating that the RMSE is close to the SD. After the bias correction, the RMSE is further reduced, and the RSR remains low (Fig. 10f), suggesting that the biascorrected reforecasts better capture the variability in strong-storm winds. This is reflected in the percent change in strong-storm wind RMSE (Fig. 10g) that shows decreases in error in the eastern North Atlantic Ocean and over land. The findings indicate that the reforecasts are already useful for the prediction of strongstorm-track-related winds at the weeks 3-4 time scales, and the bias correction leads to further improvements in both the mid- and high latitudes.

Winter precipitation associated with the strong-storm tracks in the validation period 2003-10 is presented in Fig. 11. Strong-storm-track-related precipitation in the CPC gauge-based analysis (Fig. 11a) resembles the allstorm precipitation over CONUS (see Fig. 8a), with maxima found near the west coast and in the southeastern United States. In general, winter precipitation is more intense during strong-storm activity. The uncorrected reforecast of strong-storm precipitation (Fig. 11b) shares a similar spatial distribution to observations despite overestimations in precipitation intensity. Figure 11c shows that the strong-storm precipitation in the bias-corrected reforecasts is reduced and more closely resembles observations. This is evident near the west coast and in the eastern United States.

The influence of the bias correction on strong-storm precipitation in CFSRR is depicted in Figs. 11d-g. As is shown for the all-storm precipitation, the SD of strongstorm precipitation is highest in the west and southeastern United States (Fig. 11d). The RMSE of uncorrected strong-storm precipitation (Fig. 11e, contours) reveals large errors where the SD is high. The corresponding RSR (Fig. 11e, color shades) is larger in regions with low precipitation and lower in regions with high precipitation. The large RMSE and RSR are somewhat reduced after the bias correction (Fig. 11f). Despite the improvements, large biases in the corrected precipitation rates remain throughout much of CONUS. The percent change in RMSE for strong-storm precipitation (Fig. 11g) exhibits larger decreases in errors in regions that experience lower variability in strong-storm precipitation (see Fig. 11d). Smaller reductions in error are found in areas where the variability in strong-storm precipitation is high. The results suggest that the bias correction in all-storm precipitation somewhat improves the representation of strong-storm precipitation in the weeks 3-4 reforecasts in CONUS. However, the reforecasts better capture the signal in precipitation in the all-storm tracks, suggesting that further analysis of more extreme precipitation is needed.

\section{b. High-impact weather related to the strong-storm tracks}

In this article, high-impact or severe weather related to strong storms refers to hazardous winds or heavy precipitation. More specifically, following Klawa and Ulbrich (2003) hazardous near-surface wind speeds are those whose magnitudes exceed the 98th percentile (fall within the top $2 \%$ ) of all wind speeds. Likewise, highimpact/hazardous precipitation rates are defined as those that exceed the local 98th percentile, assuming that they are most likely to produce damage and loss.

For our computations, the $98 \%$ thresholds of wind and precipitation are obtained from all winds and precipitation for the base period (1983-2002) reanalysis regardless of the presence of storms, that is, before any storm tracking is performed. Thresholds are computed for each winter and averaged to obtain a mean "climate" threshold. Then, strong-storm-track-related winds or precipitation in the reforecasts during the validation period (2003-10) are considered hazardous and likely to produce damages if they exceed the corresponding climate threshold. This is done in order to simulate forecast mode in operations. For verification purposes, we also compute the reanalysis high-impact weather cases for the validation period. In this way, reforecasts and reanalysis can be compared directly.

Figure 12 presents hazardous strong-storm wind intensity and frequency for the validation period 2003-10. The reanalysis wind intensity (Fig. 12a) for strong storms is highest over the oceans affecting, for example, maritime operations. On average, hazardous wind speeds over water are in the range from 18 to $26 \mathrm{~m} \mathrm{~s}^{-1}$ ( $\sim 40-58 \mathrm{mph}$ ) over the open oceans near the continental coastlines. Over land, high-impact winds related to the strong-storm tracks are found primarily in the central and eastern United States where they achieve speeds that exceed $14 \mathrm{~m} \mathrm{~s}^{-1}(\sim 31 \mathrm{mph})$ on average.

Hazardous strong-storm wind speeds in 2003-10 computed from the reforecasts are presented in Fig. $12 \mathrm{~b}$. The intensities of the winds correspond well with the reanalysis in the midlatitudes, although they are slightly stronger in the storm-track regions. This suggests that the reforecasts are capable of predicting high-impact winds in winter in North America.

We further examine whether the bias correction has an effect on the prediction of high-impact winds. Figure 12c shows hazardous strong-storm wind speeds in the bias-corrected reforecasts. The bias-corrected reforecasts provide better areal coverage of hazardous 


\section{Precipitation related to PV in Strong-Storm Tracks for 2003-2010}

(a) $P R(P V)$ in Reanalysis

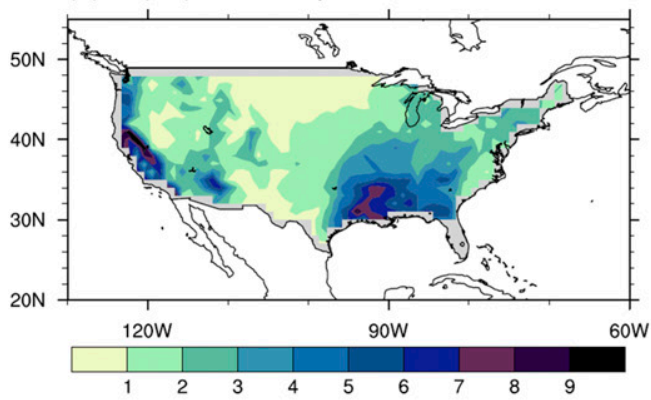

(b) $P R\left(P V_{c}\right)$ in Reforecasts

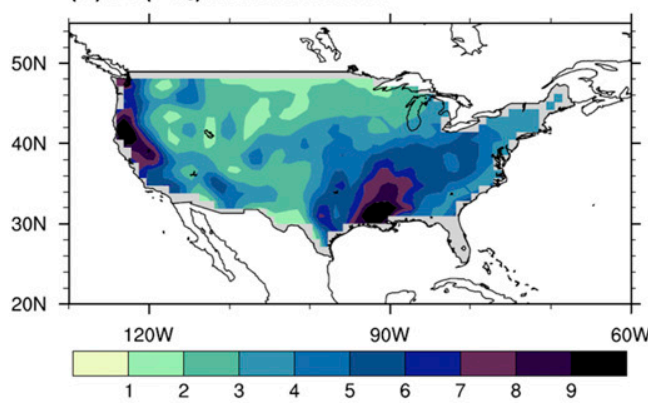

(c) $P R_{c}\left(P V_{c}\right)$ in Reforecasts

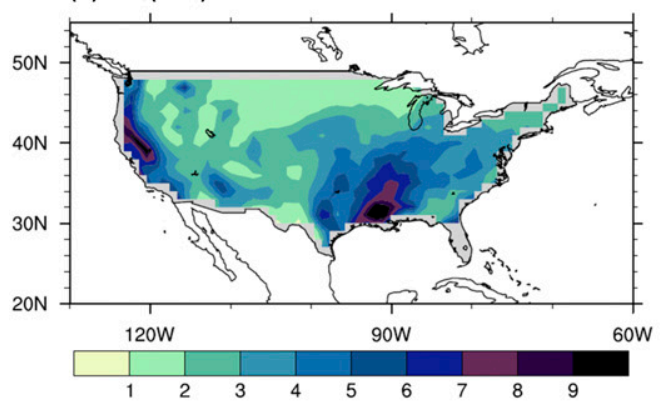

(d) SD of PR(PV) in Reanalysis

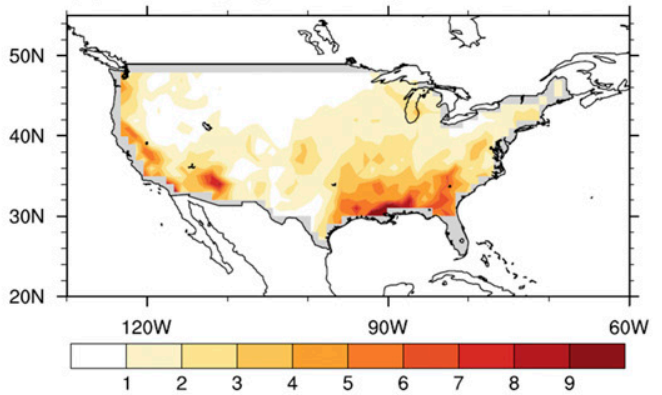

(e) RSR (colors) and RMSE for $\mathrm{PR}\left(\mathrm{PV}_{\mathrm{c}}\right)$ (contours)

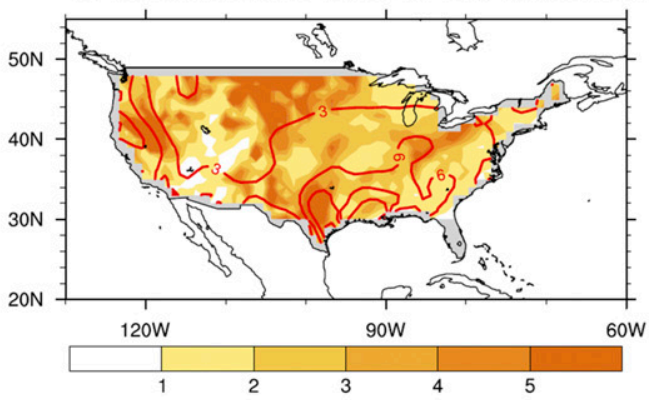

(f) RSR (colors) and RMSE for $\mathrm{PR}_{c}\left(\mathrm{PV}_{\mathrm{c}}\right)$ (contours)

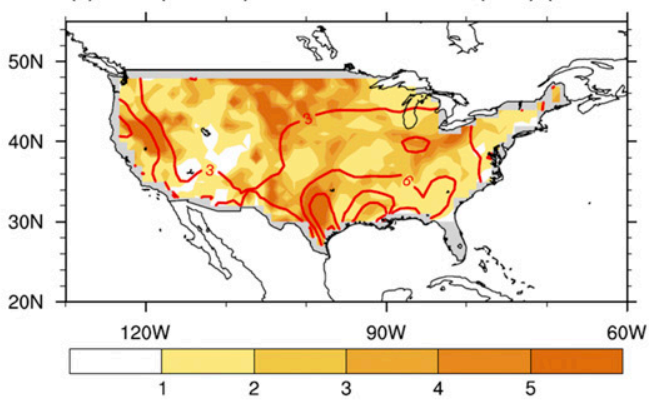

(g) \% Change in PR RMSE

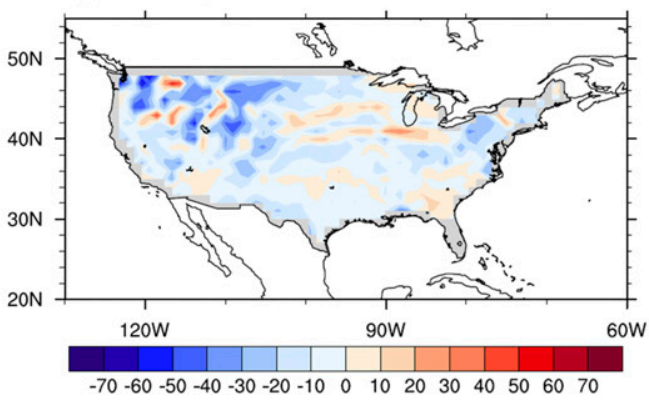

FIG. 11. Mean strong-storm-track-related daily PR during DJF for the validation period 2003-10 in the CONUS. (a) CPC gauge-based analysis PR associated with reanalysis (PV with $T_{\text {str }}=4.9$ PVU; (b) weeks 3-4 reforecast PR associated with reforecast $\mathrm{PV}_{c}$ with $T_{\text {str }}=6.1 \mathrm{PVU}$; and (c) bias-corrected weeks 3-4 reforecast $\mathrm{PR}_{c}$ associated with reforecast $\mathrm{PV}_{c}$ with $T_{\text {str }}=6.1 \mathrm{PVU}$. (d) SD of reanalysis $\mathrm{PR}(\mathrm{PV})$; (e) RMSE of weeks 3-4 reforecast $\mathrm{PR}(\mathrm{PV})$ (contours at $3 \mathrm{~mm}$ day $^{-1}$ interval) and RSR (color shades; interval 1); (f) as in (e), but for the bias-corrected $\mathrm{PR}_{c}\left(\mathrm{PV}_{c}\right)$; and $(\mathrm{g})$ percent change in RMSE after all-storm $\mathrm{PR}$ bias is removed from reforecasts, shown at an interval of $10 \%$. RSR is the ratio of RMSE of reforecast $\mathrm{PR}\left(\mathrm{PV}_{c}\right)$ to SD of reanalysis PR(PV). In (a)-(d) intervals are $1 \mathrm{~mm}$ day $^{-1}$. Areas in CONUS with missing values and less than 0.5 storms per $10^{6} \mathrm{~km}^{2}$ per month in CFSR and where strong storms are not found are masked (gray shade). 


\section{Hazardous Winds related to PV in Strong-Storm Tracks for 2003-2010}

(a) $\mathrm{V}(\mathrm{PV})$ in Reanalysis

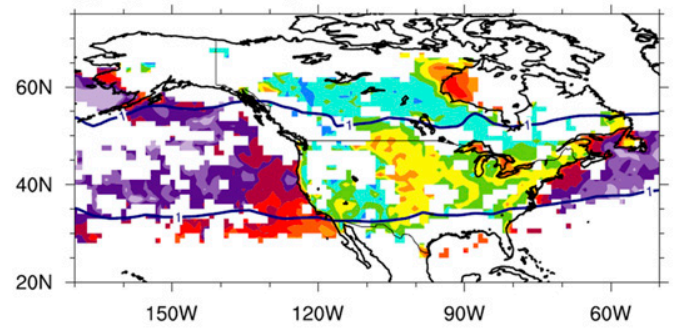

(b) $\mathrm{V}(\mathrm{PV})$ in Reforecasts

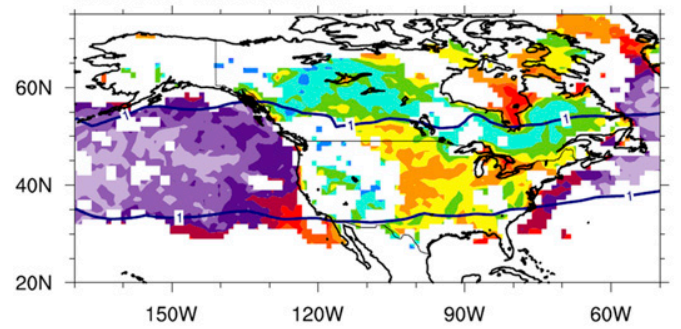

(c) $V_{c}\left(P V_{c}\right)$ in Reforecasts

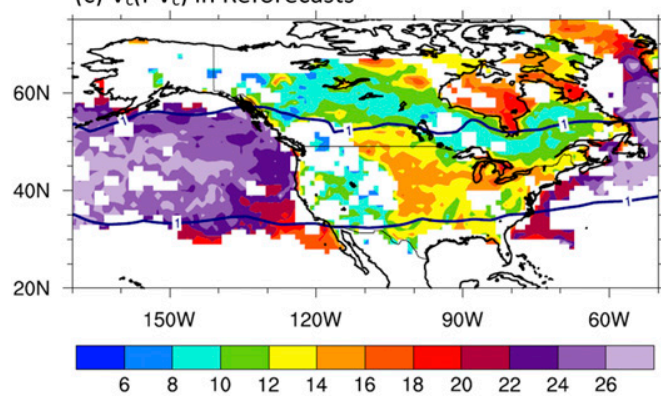

(d) Freq. Diff. of $\mathrm{V}(\mathrm{PV})$ in Reanalysis

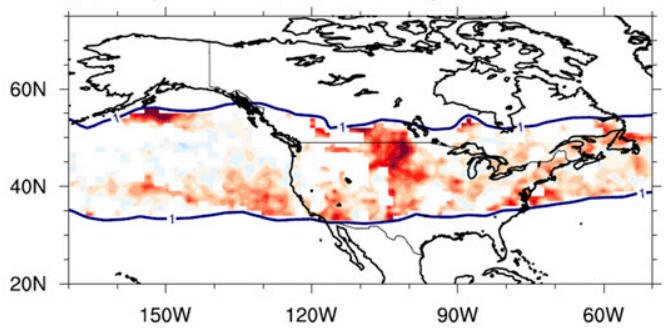

(e) Freq. Diff. of $\mathrm{V}(\mathrm{PV})$ in Reforecasts

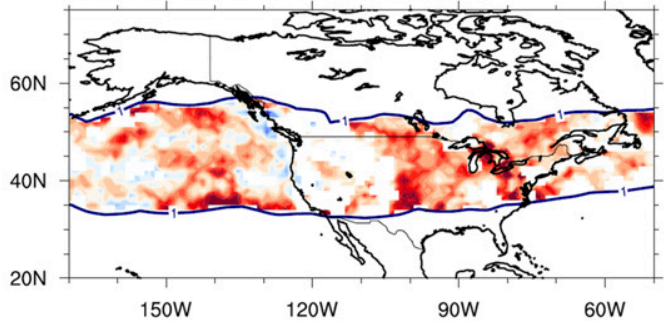

(f) Freq. Diff. of $V_{c}\left(P V_{c}\right)$ in Reforecasts

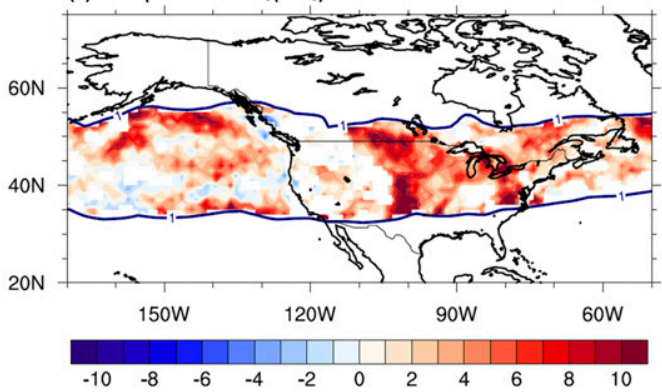

FIG. 12. Mean hazardous near-surface winds related to the strong-storm tracks during DJF for 2003-10. Wind speeds $V$ that exceed the local 98th percentile are associated with (a) CFS reanalysis PV with $T_{\text {str }}=4.9$ PVU, (b) bias-corrected reforecast $\mathrm{PV}_{c}$ with $T_{\text {str }}=6.1 \mathrm{PVU}$, and (c) bias-corrected reforecast $\mathrm{PV}_{c}$ with $T_{\text {str }}=6.1$ PVU. (d)-(f) As in (a)-(c), but showing the difference in frequency of hazardous wind events: difference in percentage of time that the local 98 th percentile is exceeded between when strong storms are present and no storms are present. Contour interval for (a)-(c) is $2 \mathrm{~m} \mathrm{~s}^{-1}$, and for (d)-(f) is $1 \%$. In all panels, the midlatitude strong-stormtrack density for CFSR is outlined by dark blue contours marking 1 strong storm per $10^{6} \mathrm{~km}^{2}$ per month. Panels (a)-(c) are masked where hazardous strong-storm winds are not found. In (d)-(f), areas outside of the strongstorm-track regions are masked.

strong-storm winds relative to the uncorrected reforecasts (Fig. 12b), although the wind magnitude does not noticeably change. This suggests that the bias correction has the potential to provide a more complete forecast of high-impact strong-storm wind intensity at weeks 3-4 time scales.

It is of interest to examine not only the severe wind magnitudes but their frequency too. Frequency is defined as the percentage of time that the local 98th percentile threshold of wind speed is exceeded. The strong storm-no storm difference in frequency of high-impact wind events in the strong-storm-track regions is shown in Figs. 12d-f. Not surprisingly, the frequency of high-impact wind events in the reanalysis increases when strong storms are present (Fig. 12d). This is particularly evident over the oceans where the storm tracks are strong and over land in areas where the winds are most intense. Wind frequency in the reforecasts is also shown to increase in the strong-storm-track regions, with the biascorrected reforecasts (Fig. 12f) providing better areal coverage of wind frequency relative to the uncorrected reforecasts (Fig. 12e). Further, the bias correction somewhat improves the change in frequency in the eastern North Pacific Ocean and central North America. In summary, we find that 1) during strong storms the frequency of hazardous wind events increases, and 2) 
the bias-corrected reforecasts better predict this increase relative to the uncorrected reforecasts.

As for heavy precipitation (not shown), the bias correction is found to offer little to no improvement in the representation of weeks 3-4 reforecasts of precipitation that exceed the local 98th percentile. Heavy precipitation intensity in the CPC gauge-based analysis resembles that shown in Fig. 11a, with the heavy precipitation intensity about one order of magnitude greater nearly everywhere in the midlatitudes. Comparisons of the weeks 3-4 reforecasts versus the bias-corrected reforecasts reveal virtually no change in the magnitude of hazardous precipitation rates. Moreover, the reforecasts are found to underestimate the magnitude of precipitation intensity in the storm-track regions relative to observations. Observations exhibit increases in the frequency of high-impact precipitation events over CONUS when strong storms are present. The uncorrected and biascorrected reforecasts overestimate precipitation frequency across CONUS, with the bias-corrected reforecasts exhibiting slightly lower values that are closer to observations (relative to the uncorrected reforecasts). The results imply that CFSRR is able to describe the spatial distributions but only the relative magnitudes of heavy strong-storm precipitation intensity and frequency at weeks 3-4 time scales.

In addition, we assess the dependence of the findings on the selected period of validation by conducting an identical strong-storm-track analysis using a 20-yr test base period (1991-2010) and an 8-yr test validation period (1983-90) in CFSRR (not shown). The results from the test analysis are generally consistent with those presented in this study. The reforecasts of storm-trackrelated winds represent well the reanalysis, and the removal of systematic errors further improves the storm-trackrelated weather reforecasts. Likewise, the reforecasts for the test validation period reproduce the characteristic hazardous strong-storm winds, again corresponding with this study's findings. Overall, the results of the test analysis indicate that our findings are robust.

\section{Summary and conclusions}

The subseasonal-to-seasonal forecast range is considered a gap in operational weather prediction, and advancements at these time scales have the potential to provide valuable information for weather-related resource management decisions across environmental and economic sectors. To contribute to the understanding of S2S weather prediction in North America, we examine to what extent the CFSRR weeks 3-4 reforecasts reproduce the dynamic properties of storm tracks, and if the latter contribute to the prediction of the expected severe weather at those time scales.
The analysis is done for two categories of storm intensity: 1) all-storm tracks, which include all extratropical cyclones, and 2) strong-storm tracks, constituted by a subset of the more intense extratropical cyclones in terms of PV. The proportion of strong storms to all storms ranges between $15 \%$ and $18 \%$ independent of region, period of analysis, and whether it was computed from reanalysis or reforecasts.

This study starts by identifying the all-storm-track properties as described from the CFS reanalysis in a 20-yr base period (1983-2002). Similar diagnostics performed over the CFS weeks 3-4 reforecasts reveal statistically significant positive biases in $\mathrm{PV}_{320}$ intensity. Once the reforecasts are bias-corrected and storm-track properties recomputed, the results are closer to those observed in the reanalysis. A good correspondence is found with previous studies that use different variables to identify storms (e.g., Hoskins and Hodges 2002; Hawcroft et al. 2016; Guo et al. 2017).

To assess the performance of the reforecasts in what would be a forecast mode in an 8-yr validation period (2003-10), we remove the 1983-2002 bias of $\mathrm{PV}_{320}$ intensity from the reforecasts. This correction reduces root mean squared errors in the PV intensity by as much as $50 \%$ in the oceanic storm-track regions. Improvements are also found in other general features of the storm tracks including their track densities as well as the cyclogenesis, and cyclolysis densities, particularly in the eastern North Pacific and western North Atlantic Oceans. The results indicate that CFSRR is capable of reproducing the dynamics of storm-track behavior at forecast weeks 3-4 after the bias is removed, suggesting that reforecast storm tracks are potentially valuable for S2S weather prediction purposes.

We next evaluate the relation of storm tracks to surface weather variables in the reforecasts to determine whether storm tracks are useful in the advancement of S2S weather prediction in North America. The spatial distributions of near-surface winds and precipitation associated with the reforecast all-storm tracks in the base period (1983-2002) resemble those of the reanalysis. However, small yet significant biases are found in the magnitude of the winds, particularly in the northeastern North Atlantic Ocean and over land east of the Rocky Mountains. The small reforecast wind error in the validation period (2003-10) is reduced on average by $12 \%$ by removing the base period wind bias. Specifically, our results show that the error is reduced over the oceans where the storm tracks are strong as well as over land in the eastern United States.

On the other hand, precipitation over the contiguous United States is overestimated near the west coast and in the southeast. The removal of the 1983-2002 
precipitation bias reduces the error in estimation for the validation period by $25 \%$ on average, although large biases remain where precipitation rates are highest. Further, after the biases are removed, the RMSE and ratio of the RMSE to the standard deviation decrease in the storm-track regions, indicating that the bias-corrected reforecasts better represent the observed variability in storm-track-related winds and precipitation.

The weeks 3-4 reforecasts represent well the strongstorm-track-related high-impact winds, as measured by wind intensity and frequency. It was shown that the reanalysis strong-storm winds are most intense over the open oceans and the eastern United States. This is also reflected in the wind reforecasts in the regions of hazardous storm winds, with the bias correction resulting in better areal coverage of predicted high-impact winds. The frequency of high-impact wind events is found to increase in the reanalysis and reforecasts when strong storms are present, with the bias-corrected reforecasts able to better predict this increase in the eastern North Pacific Ocean and central North America relative to the uncorrected reforecasts. As for precipitation that exceeds the local 98th percentile, it is found that CFSRR is able to describe the spatial distributions and relative magnitudes of heavy strong-storm precipitation intensity and frequency at weeks 3-4 time scales, with the bias correction offering little to no additional improvement.

Our findings indicate that the weeks 3-4 CFS reforecasts contain useful storm-track-related information supporting the potential use of storm-track statistics in the advancement of subseasonal prediction of hazardous weather in North America. The bias correction has a minor positive impact on the prediction of storm tracks and related weather. One note of caution is that the signal in precipitation is better captured by the all-storm tracks but not as well by the strong-storm tracks, suggesting further analysis will be needed. Yet, this step may not be necessary since our approach would be best used in current versions of CFS, requiring recomputation of the biases and new statistics.

The bias correction used here is a simple method and takes little time to process, and this is advantageous for the rapid release of severe weather forecasts. For applications in real time, the approach will require new computations of the statistics and biases in the operational forecasts of the corresponding model, for example, the CFSv2 model. The reason is that statistics and biases are model-version dependent and are affected by updates to the model.

Despite the promising results, regions where the ratio of error to standard deviation is greater than 1 suggest little skill in the model forecasts. PV best represents the storm tracks because it encompasses their dynamic and thermodynamic properties. On the other hand, the strong winds and precipitation related to the storm tracks are more directly linked to user applications, in particular for decisions regarding disaster mitigation and storm-related resource management. The counterpart is that these quantities are noisier fields and thus more difficult to verify relative to less challenging variables like SLP (e.g., Yang et al. 2015; Guo et al. 2017). A second factor that adds uncertainty is the use of a single model, the CFSv2. Studies have shown that multimodel ensembles produce more skillful forecasts at longer lead times than any individual model (e.g., Hagedorn et al. 2005; Tebaldi and Knutti 2007). The approach proposed here can be applied to different operational model forecasts in an ensemble mode, like the system known as the North American Multi-Model Ensemble (NMME; Kirtman et al. 2014), or the recently established Subseasonal Experiment (SubX; Pegion et al. 2018, manuscript submitted to Bull. Amer. Meteor. Soc.), a multimodel subseasonal experiment. Both the NMME and SubX multimodel ensembles have been found to produce more skillful, better-quality seasonal and subseasonal forecasts, respectively, than any single member. We expect that our approach in an ensemble forecast system would further improve the quality of the weeks 3-4 forecasts of storm tracks and related weather, generating more robust results. We intend to explore the value of storm track diagnostics in ensemble forecasts for North America in a future study.

Acknowledgments. The authors are thankful to the anonymous reviewers for their comments and suggestions that considerably improved the article. We also thank Kevin Hodges for his support with the methodology as well as Da-Lin Zhang and Patrick Meyers for their helpful suggestions. This work was funded under the NOAA Grant NA14NES4320003.

\section{REFERENCES}

Baldwin, M. P., and T. J. Dunkerton, 2001: Stratospheric harbingers of anomalous weather regimes. Science, 294, 581-584, https://doi.org/10.1126/science.1063315.

Booth, J. F., H. E. Rieder, D. E. Lee, and Y. Kushnir, 2015: The paths of extratropical cyclones associated with wintertime high-wind events in the northeastern United States. J. Appl. Meteor. Climatol., 54, 1871-1885, https://doi.org/10.1175/ JAMC-D-14-0320.1.

_ C. M. Naud, and J. Willison, 2018: Evaluation of extratropical cyclone precipitation in the North Atlantic basin: An analysis of ERA-Interim, WRF, and two CMIP5 models. J. Climate, 31, 2345-2360, https://doi.org/10.1175/JCLI-D-17-0308.1.

Brayshaw, D. J., B. Hoskins, and M. Blackburn, 2009: The basic ingredients of the North Atlantic storm track. Part I: Land-sea 
contrast and orography. J. Atmos. Sci., 66, 2539-2558, https:// doi.org/10.1175/2009JAS3078.1.

Brunet, G., and Coauthors, 2010: Collaboration of the weather and climate communities to advance subseasonal to seasonal prediction. Bull. Amer. Meteor. Soc., 91, 1397-1406, https:// doi.org/10.1175/2010BAMS3013.1.

Catto, J. L., C. Jakob, G. Berry, and N. Nicholls, 2012: Relating global precipitation to atmospheric fronts. Geophys. Res. Lett., 39, L10805, https://doi.org/10.1029/2012GL051736.

Chang, E. K. M., 2009: Diabatic and orographic forcing of northern winter stationary waves and storm tracks. J. Climate, 22, 670-688, https://doi.org/10.1175/2008JCLI2403.1.

_ - S. Lee, and K. L. Swanson, 2002: Storm track dynamics. J. Climate, 15, 2163-2183, https://doi.org/10.1175/15200442(2002)015<02163:STD>2.0.CO;2.

Chen, M., W. Shi, P. Xie, V. B. S. Silva, V. E. Kousky, R. W. Higgins, and J. E. Janowiak, 2008: Assessing objective techniques for gauge-based analyses of global daily precipitation. J. Geophys. Res., 113, D04110, https://doi.org/10.1029/ 2007JD009132.

Davis, R. E., and R. Dolan, 1993: Nor'easters. Amer. Sci., 81, 428-439.

Field, P. R., and R. Wood, 2007: Precipitation and cloud structure in midlatitude cyclones. J. Climate, 20, 233-254, https:// doi.org/10.1175/JCLI3998.1.

Garreaud, R., 2007: Precipitation and circulation covariability in the extratropics. J. Climate, 20, 4789-4797, https://doi.org/ 10.1175/JCLI4257.1.

Grise, K. M., S.-W. Son, and J. R. Gyakum, 2013: Intraseasonal and interannual variability in North American storm tracks and its relationship to equatorial Pacific variability. Mon. Wea. Rev., 141, 3610-3625, https://doi.org/10.1175/MWR-D-12-00322.1.

Guo, Y., T. Shinoda, J. Lin, and E. K. M. Chang, 2017: Variations of Northern Hemisphere storm track and extratropical cyclone activity associated with the Madden-Julian oscillation. J. Climate, 30, 4799-4818, https://doi.org/10.1175/JCLI-D-160513.1.

Hagedorn, R., F. J. Doblas-Reyes, and T. N. Palmer, 2005: The rationale behind the success of multi-model ensembles in seasonal forecasting - I. Basic concept. Tellus, 57A, 219-233, https://doi.org/10.1111/j.1600-0870.2005.00103.x.

Hawcroft, M. K., L. C. Shaffrey, K. I. Hodges, and H. F. Dacre, 2012: How much Northern Hemisphere precipitation is associated with extratropical cyclones? Geophys. Res. Lett., 39, L24809, https://doi.org/10.1029/2012GL053866.

$-, \ldots, \ldots$, and $\_, 2016$ : Can climate models represent the precipitation associated with extratropical cyclones? Climate Dyn., 47, 679-695, https://doi.org/10.1007/s00382-015-2863-z.

Hodges, K. I., 1996: Spherical nonparametric estimators applied to the UGAMP model integration for AMIP. Mon. Wea. Rev., 124, 2914-2932, https://doi.org/10.1175/1520-0493(1996) 124<2914:SNEATT>2.0.CO;2.

_ 1999: Adaptive constraints for feature tracking. Mon. Wea. Rev., 127, 1362-1373, https://doi.org/10.1175/1520-0493(1999) $127<1362$ :ACFFT $>2.0 . \mathrm{CO} ; 2$.

- 2008: Confidence intervals and significance tests for spherical data derived from feature tracking. Mon. Wea. Rev., 136, 1758-1777, https://doi.org/10.1175/2007MWR2299.1.

Holman, B. P., S. M. Lazarus, and M. E. Splitt, 2017: A fetch-based statistical method to bias correct and downscale wind speed over unresolved water bodies. Wea. Forecasting, 32, 16371657, https://doi.org/10.1175/WAF-D-17-0016.1.
Holton, J. R., 2004: An Introduction to Dynamic Meteorology. 4th ed. International Geophysics Series, Vol. 88, Academic Press, $535 \mathrm{pp}$.

Hoskins, B. J., 2015: Potential vorticity and the PV perspective. Adv. Atmos. Sci., 32, 2-9, https://doi.org/10.1007/s00376-0140007-8.

— , and K. I. Hodges, 2002: New perspectives on the Northern Hemisphere winter storm tracks. J. Atmos. Sci., 59, 1041-1061, https://doi.org/10.1175/1520-0469(2002)059<1041:NPOTNH> 2.0.CO;2.

— M. E. McIntyre, and A. W. Robertson, 1985: On the use and significance of isentropic potential vorticity maps. Quart. J. Roy. Meteor. Soc., 111, 877-946, https://doi.org/10.1002/ qj. 49711147002.

Karl, T. R., G. A. Meehl, C. D. Miller, S. J. Hassol, A. M. Waple, and W. L. Murray, Eds., 2008: Weather and climate extremes in a changing climate-Regions of focus: North America, Hawaii, Caribbean, and U.S. Pacific Islands. U.S. Climate Change Science Program and the Subcommittee on Global Change Research Synthesis and Assessment Product 3.3, 180 pp.

Kirtman, B. P., and Coauthors, 2014: The North American Multimodel Ensemble: Phase-1 seasonal-to-interannual prediction; Phase-2 toward developing intraseasonal prediction. Bull. Amer. Meteor. Soc., 95, 585-601, https://doi.org/10.1175/ BAMS-D-12-00050.1.

Klawa, M., and U. Ulbrich, 2003: A model for the estimation of storm losses and the identification of severe winter storms in Germany. Nat. Hazards Earth Syst. Sci., 3, 725-732, https:// doi.org/10.5194/nhess-3-725-2003.

Kunkel, K. E., R. A. Pielke Jr., and S. A. Changnon, 1999: Temporal fluctuations in weather and climate extremes that cause economic and human health impacts: A review. Bull. Amer. Meteor. Soc., 80, 1077-1098, https://doi.org/10.1175/15200477(1999)080<1077:TFIWAC $>2.0$. CO;2.

, D. R. Easterling, D. A. R. Kristovich, B. Gleason, L. Stoecker, and R. Smith, 2012: Meteorological causes of the secular variations in observed extreme precipitation events for the conterminous United States. J. Hydrometeor., 13, 1131-1141, https://doi.org/10.1175/JHM-D-11-0108.1.

_, and Coauthors, 2013: Monitoring and understanding trends in extreme storms: State of knowledge. Bull. Amer. Meteor. Soc., 94, 499-514, https://doi.org/10.1175/BAMS-D-1100262.1.

Lawrimore, J., T. R. Kari, and M. Squires, 2014: Trends and variability of severe snowstorms east of the Rocky Mountains. J. Hydrometeor., 15, 1762-1777, https://doi.org/10.1175/JHMD-13-068.1.

Leckebusch, G. C., D. Renggli, and U. Ulbrich, 2008: Development and application of an objective storm severity measure for the northeast Atlantic region. Meteor. Z., 17, 575-587, https:// doi.org/10.1127/0941-2948/2008/0323.

Lukens, K. E., E. H. Berbery, and K. I. Hodges, 2018: The imprint of strong-storm tracks on winter weather in North America. J. Climate, 31, 2057-2074, https://doi.org/10.1175/JCLI-D-170420.1 .

Ma, C.-G., and E. K. M. Chang, 2017: Impacts of storm-track variations on wintertime extreme weather events over the continental United States. J. Climate, 30, 4601-4624, https:// doi.org/10.1175/JCLI-D-16-0560.1.

Mailier, P. J., D. B. Stephenson, C. A. T. Ferro, and K. I. Hodges, 2006: Serial clustering of extratropical cyclones. Mon. Wea. Rev., 134, 2224-2240, https://doi.org/10.1175/MWR3160.1. 
Moriasi, D. N., J. G. Arnold, M. W. Van Liew, R. L. Bingner, R. D. Harmel, and T. L. Veith, 2007: Model evaluation guidelines for systematic quantification of accuracy in watershed simulations. Trans. ASABE, 50, 885-900, https://doi.org/10.13031/ 2013.23153.

Pfahl, S., and H. Wernli, 2012: Quantifying the relevance of cyclones for precipitation extremes. J. Climate, 25, 6770-6780, https://doi.org/10.1175/JCLI-D-11-00705.1.

Pielke, R., Jr., and R. E. Carbone, 2002: Weather impacts, forecasts, and policy. Bull. Amer. Meteor. Soc., 83, 393-403, https:// doi.org/10.1175/1520-0477(2002)083<0393:WIFAP>2.3.CO;2.

Saha, S., and Coauthors, 2010a: NCEP Climate Forecast System Reanalysis (CFSR) 6-hourly products, January 1979 to December 2010. NCAR Computational and Information Systems Laboratory Research Data Archive, accessed 11 March 2014, https://doi.org/10.5065/D69K487J.

, and Coauthors, 2010b: The NCEP Climate Forecast System Reanalysis. Bull. Amer. Meteor. Soc., 91, 1015-1057, https:// doi.org/10.1175/2010BAMS3001.1.

— , and Coauthors, 2014a: NCEP Climate Forecast System Reforecast products, December 1981 to March 2011. NOAA National Centers for Environmental Information, accessed 20 October 2017, https:// www.ncdc.noaa.gov/data-access/model-data/model-datasets/ climate-forecast-system-version2-cfsv2\#CFS\%20Reforecasts.

— , and Coauthors, 2014b: The NCEP Climate Forecast System version 2. J. Climate, 27, 2185-2208, https://doi.org/10.1175/ JCLI-D-12-00823.1.

Salathé, E. P., Jr., 2006: Influences of a shift in North Pacific storm tracks on western North American precipitation under global warming. Geophys. Res. Lett., 33, L19820, https://doi.org/ 10.1029/2006GL026882.

Shapiro, M., and Coauthors, 2010: An Earth-system prediction initiative for the twenty-first century. Bull. Amer. Meteor. Soc., 91, 1377-1388, https://doi.org/10.1175/2010BAMS2944.1.

Sweeney, C. P., P. Lynch, and P. Nolan, 2013: Reducing errors of wind speed forecasts by an optimal combination of postprocessing methods. Meteor. Appl., 20, 32-40, https://doi.org/ 10.1002/met.294.

Tebaldi, C., and R. Knutti, 2007: The use of the multi-model ensemble in probabilistic climate projections. Philos. Trans.
Roy. Soc. London, A365, 2053-2075, https://doi.org/10.1098/ rsta.2007.2076.

Vitart, F., A. W. Robertson, and D. L. T. Anderson, 2012: Subseasonal to seasonal prediction project: Bridging the gap between weather and climate. WMO Bull., 61, 23-28.

— , and Coauthors, 2017: The Subseasonal to Seasonal (S2S) prediction project database. Bull. Amer. Meteor. Soc., 98, 163-173, https://doi.org/10.1175/BAMS-D-16-0017.1.

Wang, W., P. Xie, S. H. Yoo, Y. Xue, A. Kumar, and X. Wu, 2011: An assessment of the surface climate in the NCEP climate forecast system reanalysis. Climate Dyn., 37, 1601-1620, https://doi.org/10.1007/s00382-010-0935-7.

Wang, Y., Q. Wang, and J. E. Taylor, 2017: Aggregated responses of human mobility to severe winter storms: An empirical study. PLOS ONE, 12, e0188734, https://doi.org/10.1371/ journal.pone.0188734.

White, C. J., and Coauthors, 2017: Potential applications of subseasonal-to-seasonal (S2S) predictions. Meteor. Appl., 24, 315-325, https://doi.org/10.1002/met.1654.

Xie, P., A. Yatagai, M. Chen, T. Hayasaka, Y. Fukushima, C. Liu, and S. Yang, 2007: A gauge-based analysis of daily precipitation over East Asia. J. Hydrometeor., 8, 607-626, https:// doi.org/10.1175/JHM583.1.

_, M. Chen, and W. Shi, 2010: CPC unified gauge-based analysis of global daily precipitation. 24th Conf. on Hydrology, Atlanta, GA, Amer. Meteor. Soc., 2.3A, https://ams.confex.com/ams/ 90annual/webprogram/Paper163676.html.

Yang, X., and Coauthors, 2015: Seasonal predictability of extratropical storm tracks in GFDL's high-resolution climate prediction model. J. Climate, 28, 3592-3611, https://doi.org/ 10.1175/JCLI-D-14-00517.1.

Zheng, C., E. K.-M. Chang, H.-M. Kim, and M. Zhang, 2018: Impacts of the Madden-Julian oscillation on storm-track activity, surface air temperature, and precipitation over North America. J. Climate, 31, 6113-6134, https://doi.org/10.1175/JCLI-D 17-0534.1.

Zhu, Y., and Y. Luo, 2015: Precipitation calibration based on the frequency-matching method. Wea. Forecasting, 30, 1109-1124, https://doi.org/10.1175/WAF-D-13-00049.1. 